\title{
A Comparative Study of f-Element Electronic Structure across a Series of Multimetallic Actinide, Lanthanide- Actinide and Lanthanum-Actinide Complexes Possessing Redox-Active Bridging Ligands
}

\author{
Eric J. Schelter ${ }^{\dagger}$, Ruilian $\mathrm{Wu}^{\dagger}$, Jacqueline M. Veauthier ${ }^{\dagger}$, Eric D. Bauer ${ }^{\dagger}$, Corwin H. Booth ${ }^{\ddagger}$, \\ Robert K. Thomson ${ }^{\dagger}$, Christopher R. Graves ${ }^{\dagger}$, Kevin D. John $^{\dagger}$, Brian L. Scott ${ }^{\dagger}$, \\ Joe D. Thompson ${ }^{\dagger}$, David E. Morris ${ }^{\star}{ }^{\dagger}$, and Jaqueline L. Kiplinger ${ }^{\star}{ }^{\dagger}$ \\ ${ }^{\dagger}$ Los Alamos National Laboratory, \\ Los Alamos, NM 87545 (USA) \\ E-mail: demorris@lanl.gov (D.E.M.), kiplinger@lanl.gov (J. L. K.) \\ ${ }^{\ddagger}$ Lawrence Berkeley National Laboratory, \\ Chemical Sciences Division, \\ Berkeley, CA 94720 (USA)
}

RECEIVED DATE (to be automatically inserted after your manuscript is accepted if required according to the journal that you are submitting your paper to)

KEYWORDS: uranium, thorium, lanthanide, electrochemistry, electronic coupling, actinidemediated metal-metal interaction/communication, X-ray absorption spectroscopy 


\section{Abstract}

A comparative examination of the electronic interactions across a series of trimetallic actinide and mixed lanthanide-actinide and lanthanum-actinide complexes is presented. Using reduced, radical terpyridyl ligands as conduits in a bridging framework to promote intramolecular metal-metal communication, studies containing structural, electrochemical, and X-ray absorption spectroscopy are presented for $\left(\mathrm{C}_{5} \mathrm{Me}_{5}\right)_{2} \mathrm{An}[-$ $\left.\mathrm{N}=\mathrm{C}(\mathrm{Bn})\left(\mathrm{tpy}-\mathrm{M}\left\{\mathrm{C}_{5} \mathrm{Me}_{4} \mathrm{R}\right\}_{2}\right)\right]_{2}\left(\right.$ where $\mathrm{An}=\mathrm{Th}^{\mathrm{IV}}, \mathrm{U}^{\mathrm{IV}} ; \mathrm{Bn}=\mathrm{CH}_{2} \mathrm{C}_{6} \mathrm{H}_{5} ; \mathrm{M}=\mathrm{La}^{\mathrm{III}}, \mathrm{Sm} \mathrm{Sm}^{\mathrm{III}}, \mathrm{Yb}^{\mathrm{III}}$, $\left.U^{\prime \prime \prime} ; R=H, M e, E t\right)$ to reveal effects dependent on the identities of the metal ions and $R-$ groups. The electrochemical results show differences in redox energetics at the peripheral " $\mathrm{M}$ " site between complexes and significant wave splitting of the metal- and ligand-based processes indicating substantial electronic interactions between multiple redox sites across the actinide-containing bridge. Most striking is the appearance of strong electronic coupling for the trimetallic $Y b^{\prime \prime \prime}-U^{I V}-Y b^{\prime \prime \prime}, S m^{\prime \prime \prime}-U^{I V}-S m^{I I \prime}$, and $L a^{I I I}-U^{I V}-$ La $^{\prime \prime \prime}$ complexes, $[\mathbf{8}]^{-},[\mathbf{9 b}]^{-}$and [10b]', respectively, whose calculated comproportionation constant $K_{c}$ is slightly larger than that reported for the benchmark Creutz-Taube ion. Xray absorption studies for monometallic metallocene complexes of $U^{\prime \prime \prime}, U^{I V}$, and $U^{\vee}$ reveal small but detectable energy differences in the "white-line" feature of the uranium

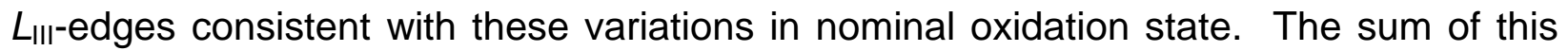
data provides evidence of $5 \mathrm{f} / 6 \mathrm{~d}$-orbital participation in bonding and electronic delocalization in these multimetallic f-element complexes. An improved, high-yielding synthesis of $4^{\prime}$-cyano-2,2':6',2"-terpyridine is also reported. 


\section{Introduction}

In the descriptive chemistry of f-element complexes, the valence f-orbital radial extensions of the lanthanide series are considered core-like; whereas, the valence 5f-orbitals in the actinide series often exhibit appreciable overlap with ligand orbitals. With substantial extension of $5 f-$ orbitals from the core, early actinide compounds (Th-Pu) have shown signatures of significant covalent metal-ligand bonding, giving rise to unique chemical and physicochemical properties. ${ }^{1-8}$

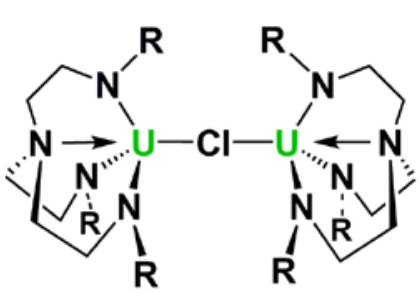

1: $U^{I I I / U^{I V}}$

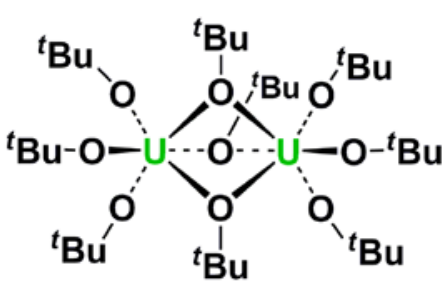

2: $U^{I V} / U^{V}$

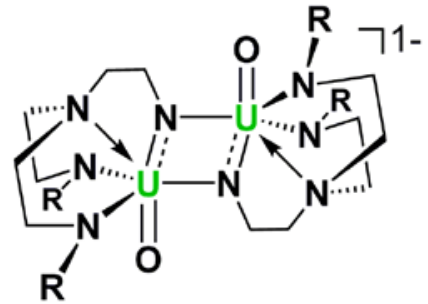

3: $U^{\mathrm{V}} / \mathrm{U}^{\mathrm{VI}}$

Chart 1. Examples of reported mixed-valent uranium complexes $\left(\mathrm{R}=\mathrm{Si}^{t} \mathrm{BuMe}_{2}\right)$.

The introduction of multiple metal ions into structural frameworks known to exhibit f-element metal-ligand covalency creates the possibility for metal-metal electronic delocalization and mixed-valency. The ability of f-element materials to form mixed-valent species has direct consequences on their corrosion, speciation, and environmental chemistry. For example, actinyl "cation-cation" complexes, resulting from metal $\cdots$ oxo $[\mathrm{O}=\mathrm{An}=\mathrm{O}]^{\mathrm{n}+} \cdots \mathrm{AnO}_{2}$ interactions, are considered important in this context. ${ }^{9-11}$

A few examples of mixed-valent uranium complexes have appeared in the literature and include the uranium bimetallic systems $\left[\mathrm{N}\left\{\mathrm{CH}_{2} \mathrm{CH}_{2} \mathrm{~N}\left(\mathrm{Si}^{t} \mathrm{BuMe}_{2}\right)\right\}_{3} \mathrm{U}\right]_{2}(\mu-\mathrm{Cl})(\mathbf{1}),{ }^{12} \mathrm{U}_{2}\left(\mathrm{O}^{t} \mathrm{Bu}\right)_{9}$ (2), ${ }^{13}$ and $\left[\mathrm{K}(18-\mathrm{crown}-6)\left(\mathrm{Et}_{2} \mathrm{O}\right)\right]\left[\mathrm{UO}\left\{\mu_{2}-\mathrm{NCH}_{2} \mathrm{CH}_{2} \mathrm{~N}\left(\mathrm{CH}_{2} \mathrm{CH}_{2} \mathrm{~N}\left(\mathrm{Si}^{t} \mathrm{BuMe}_{2}\right)\right)_{2}\right\}\right]_{2}$ (3), ${ }^{14}$ which reportedly exhibit canonical $\mathrm{U}^{\mathrm{III}} / \mathrm{U}^{\mathrm{IV}}, \mathrm{U}^{\mathrm{IV}} / \mathrm{U}^{\mathrm{V}}$, and $\mathrm{U}^{\mathrm{V}} / \mathrm{U}^{\mathrm{VI}}$ valences, respectively (Chart 1). The chloride ligand of complex 1 resides on a crystallographic inversion center with a $\mathrm{U}-\mathrm{Cl}$ distance of 3.020(1) $\AA$, which is intermediate between the expected values for uranium(III)- and 
uranium(IV)-chloride distances; the complex was assigned as a species with intermediate uranium valencies. $^{12,15}$ Complex 2 features uranium-bridging alkoxide distances of $\mathrm{U}(1)-\mathrm{O}=$ 2.069(6), 2.258(11) $\AA$ and U(2)-O = 2.105(1), 2.49(2) $\AA$. The authors described the valence of 2 as "trapped" $\mathrm{U}^{\mathrm{IV}} / \mathrm{U}^{\mathrm{V}}$ on the basis of these crystallographic differences and optical spectroscopic evidence. ${ }^{13}$ As such, the presence of an inversion center in $\mathbf{1}$ nominally indicates delocalization, but the similar uranium-alkoxide bond lengths for the valence-localized 2 demonstrate that crystallographic distances are neither reliable nor precise for unambiguous determination of the presence and extent of electronic communication for multimetallic uranium complexes.

Evidence for a delocalized electron was presented for 3, which also crystallizes on an inversion center and is the most thoroughly characterized of complexes 1-3. ${ }^{14}$ EPR, XAS, and UV-visible-near-IR absorption measurements on $\mathbf{3}$ are not self-consistent. The IR spectrum of $\mathbf{3}$ exhibited a single $\mathrm{U}=\mathrm{O}$ stretching mode at $827 \mathrm{~cm}^{-1}$ consistent with delocalization, while the electrochemistry of $\mathbf{3}$ exhibited a quasi-reversible reduction and irreversible oxidation process, which both suffered from decomposition of the complex on potential cycling. A comproportionation constant of $K_{c} \approx 10^{18}$ calculated for $\mathbf{3}$ from the estimated potential difference between the oxidation and reduction events showed the large stability of the mixed-valent form. For comparison, $K_{c}=10^{6.6}$ for the Creutz-Taube complex. ${ }^{16}$ These intriguing results for 3 indicated the ability of the 5f-orbitals of uranium to mix strongly enough with the ligand orbitals to produce a valence-delocalized complex. Most other conclusions of mixed-valent behavior in molecular uranium species are based on crystallographic characterization as primary evidence for their delocalized electronic structures. ${ }^{17-23}$ A few more-scrupulously characterized compounds also include magnetic data; however, these data can be ambiguous due to the similar ligand-field energies of $5 f^{1}, 5 f^{2}$ and $5 f^{3}$ ions. ${ }^{24}$ Overall, other than 3 , the reported systems to date are insufficiently characterized to quantify extents of electronic coupling. Furthermore, systematic 
investigation of electronic delocalization in these systems was hampered by their synthetic inflexibility.

We have been investigating electronic and magnetic communication in actinide and mixed actinide-lanthanide molecular complexes. ${ }^{25-28}$ As part of these efforts, we reported the synthesis and comprehensive physicochemical characterization of uranium(IV)- and thorium(IV)bis(ketimide) complexes (Chart 2). Complexes $\mathbf{4 a - b}$ and $\mathbf{5 a - b}$ were prepared by insertion of benzonitrile and 4'-cyano-2,2':6',2"-terpyridine, respectively, into the actinide- $\mathrm{C}_{\text {benzyl }}$ bonds of $\left(\mathrm{C}_{5} \mathrm{Me}_{5}\right)_{2} \mathrm{An}\left(\mathrm{CH}_{2} \mathrm{C}_{6} \mathrm{H}_{5}\right)_{2}(\mathrm{An}=\mathrm{Th}, \mathrm{U}) .{ }^{6,25}$ We have observed that $\mathbf{4 a - b}$ and $\mathbf{5 a - b}$ and related systems show distinct characteristics of metal-ketimide ligand covalency in bonding as judged experimentally through ground- and excited-state electronic absorption spectroscopy, ${ }^{8,29-32}$ electrochemistry, ${ }^{30}$ and magnetic susceptibility studies, ${ }^{30}$ complimented by density functional theory (DFT) and time-dependent density functional theory (TD-DFT) calculations. ${ }^{7,30,31}$

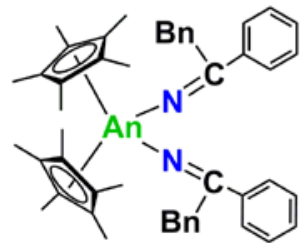

$\mathrm{Bn}=\mathrm{CH}_{2} \mathrm{C}_{6} \mathrm{H}_{5}$

$A n=T h(\mathbf{4 a}), \cup(\mathbf{4 b})$

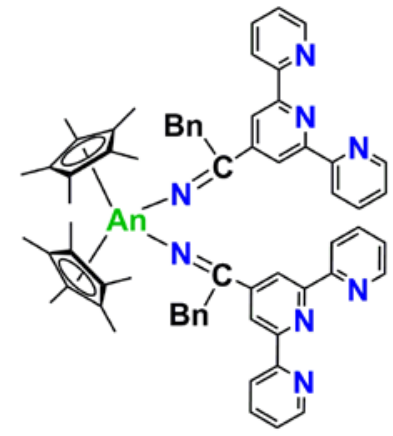

$A n=T h(5 a), U(5 b)$

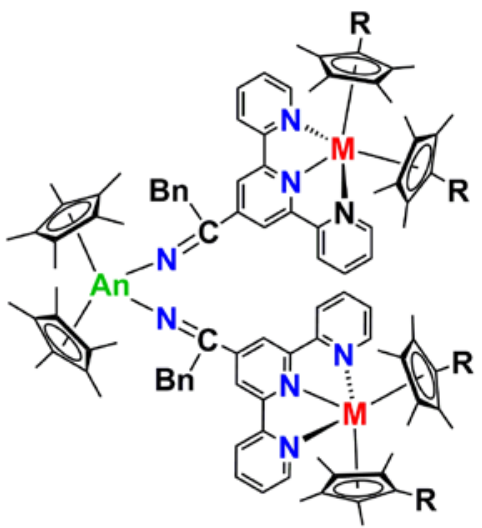

$A n=T h, M=Y b, R=M e(6 a)$

$A n=U, M=Y b, R=M e(6 b)$

$\mathrm{An}=\mathrm{Th}, \mathrm{M}=\mathrm{U}, \mathrm{R}=\mathrm{Et}(\mathbf{7 a})$

$A n=U, M=U, R=$ Et $(7 b)$

Chart 2. Reported actinide bis(ketimide) complexes including multimetallic systems.

The terpyridyl groups in complexes $\mathbf{5 a - b}$ provide a platform for the introduction of additional metal ions. Reaction of 5a-b with f-element metal ions produced the homo- and heterotrimetallic 
complexes 6a-b and 7a-b. Electrochemical data for these complexes revealed evidence for electronic interaction between the peripheral f-element metal ions by a through-bond mechanism facilitated by the central, bridging actinide ion and its ketimide ligand coordination environment. Further, the magnitude of the interaction varied depending on the identity of $\mathrm{An}=\mathrm{Th}, \mathrm{U}$ and $\mathrm{M}=$ Yb, U. Herein, we expand this work to a series of structurally related complexes and present a systematic study of their redox properties with the ability to insert a selection of metal ions at the "M" position shown in Chart 2. Of specific interest is the appearance and modulation of electronic coupling across 5f-element ions bridged between redox centers in these complexes. We also report our initial efforts to use X-ray absorption spectroscopy for this class of $\left(\mathrm{C}_{5} \mathrm{Me}_{5}\right)_{2} \mathrm{An}$ organometallic actinide complexes for the elucidation of metal oxidation state.

\section{Results and Discussion}

Synthesis and Structural Chemistry. The formation of 5a-b in high yields provides a useful starting point for the development of multimetallic assemblies. As illustrated in Scheme 1, reaction of 2 equiv. of the divalent lanthanide complex $\left(\mathrm{C}_{5} \mathrm{Me}_{5}\right)_{2} \mathrm{Yb}\left(\mathrm{OEt}_{2}\right)$ with $\mathbf{5 a - b}$ provides a source of metal ion and reducing agent as this reaction produces a nominally reduced tpy ${ }^{*}$ moiety in the neutral complexes $\left(\mathrm{C}_{5} \mathrm{Me}_{5}\right)_{2} \mathrm{An}\left[-\mathrm{N}=\mathrm{C}(\mathrm{Bn})\left(\operatorname{tpy}-\mathrm{Yb}\left\{\mathrm{C}_{5} \mathrm{Me}_{5}\right\}_{2}\right)\right]_{2}(\mathrm{An}=\mathrm{Th}(\mathbf{6 a}), \mathrm{U}$ (6b)). ${ }^{25}$ In the current work, we have extended this approach to another divalent ytterbium source, $\left(\mathrm{C}_{5} \mathrm{Me}_{4} \mathrm{Et}\right)_{2} \mathrm{Yb}\left(\mathrm{OEt}_{2}\right)$. This material exhibits identical reactivity to $\left(\mathrm{C}_{5} \mathrm{Me}_{5}\right)_{2} \mathrm{Yb}\left(\mathrm{OEt}_{2}\right)$ with the advantages of having a more soluble, crystalline and stable product, $\left(\mathrm{C}_{5} \mathrm{Me}_{5}\right)_{2} \mathrm{U}[-$ $\left.\mathrm{N}=\mathrm{C}(\mathrm{Bn})\left(\mathrm{tpy}-\mathrm{Yb}\left\{\mathrm{C}_{5} \mathrm{Me}_{4} \mathrm{Et}\right\}_{2}\right)\right]_{2}(\mathbf{8})$ (Scheme 1). The use of the $\left(\mathrm{C}_{5} \mathrm{Me}_{4} \mathrm{Et}\right)^{-}$supporting ligand also confers an important crystallographic advantage as the presence of the ethyl group in this moiety eliminates the U/Yb site occupancy disorder observed in single-crystal X-ray data of $\mathbf{6 b}$. Other divalent lanthanide sources can be similarly introduced, ${ }^{33}$ as evidenced by the reaction of 
$\left(\mathrm{C}_{5} \mathrm{Me}_{4} \mathrm{Et}\right)_{2} \mathrm{Sm}(\mathrm{THF})$ with $5 \mathbf{a}-\mathbf{b}$ to give $\left(\mathrm{C}_{5} \mathrm{Me}_{5}\right)_{2} \mathrm{An}\left[-\mathrm{N}=\mathrm{C}(\mathrm{Bn})\left(\mathrm{tpy}-\mathrm{Sm}\left\{\mathrm{C}_{5} \mathrm{Me}_{4} \mathrm{Et}\right\}_{2}\right)\right]_{2}(\mathrm{An}=\mathrm{Th}$ (9a), U (9b)) (Scheme 1).

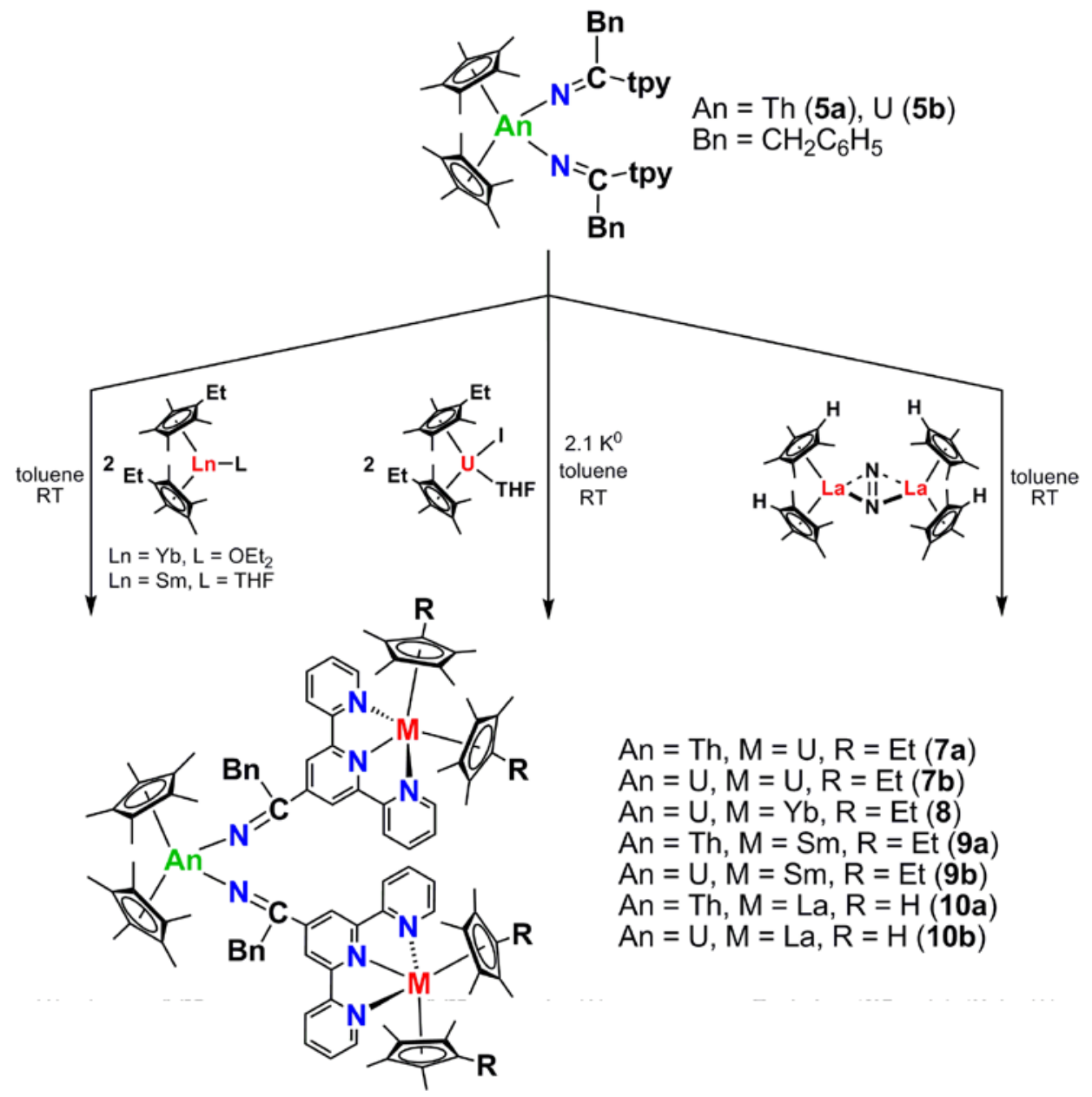

Scheme 1. Synthetic routes to the homo- and heterotrimetallic complexes $\left(\mathrm{C}_{5} \mathrm{Me}_{5}\right)_{2} \mathrm{An}^{\mathrm{IV}}\left[-\mathrm{N}=\mathrm{C}(\mathrm{Bn})\left(\mathrm{tpy} \cdot \mathrm{M}^{\mathrm{III}}\left\{\mathrm{C}_{5} \mathrm{Me}_{4} \mathrm{R}\right\}_{2}\right)\right]_{2}(\mathbf{7 - 1 0})$.

The divalent lanthanide precursors are convenient since they provide internal reducing equivalents; however, the necessary reducing equivalents for the multimetallic systems can be obtained using external means. Reaction of $\mathbf{5 a - b}$ with $\left(\mathrm{C}_{5} \mathrm{Me}_{4} \mathrm{Et}\right)_{2} \mathrm{UI}(\mathrm{THF})$ over potassium metal affords the all-actinide complexes $\left(\mathrm{C}_{5} \mathrm{Me}_{5}\right)_{2} \mathrm{An}\left[-\mathrm{N}=\mathrm{C}(\mathrm{Bn})\left(\mathrm{tpy}-\mathrm{U}\left\{\mathrm{C}_{5} \mathrm{Me}_{4} \mathrm{Et}\right\}_{2}\right)\right]_{2}(\mathrm{An}=\mathrm{Th}(7 \mathbf{a}), \mathrm{U}$ (7b)) (Chart 2 and Scheme 1). ${ }^{27}$ In a related strategy, the activated dinitrogen complex $\left[\left\{\left(\mathrm{C}_{5} \mathrm{Me}_{4} \mathrm{H}\right)_{2}(\mathrm{THF}) \mathrm{La}\right\}_{2}\left(\mu-\eta_{2}: \eta_{2}-\mathrm{N}_{2}\right)\right]^{34}$ can function as a divalent lanthanum synthon. As shown 
in Scheme 1, reaction of $\mathbf{5 a - b}$ with one equiv. $\left[\left\{\left(\mathrm{C}_{5} \mathrm{Me}_{4} \mathrm{H}\right)_{2}(\mathrm{THF}) \mathrm{La}\right\}_{2}\left(\mu-\eta_{2}: \eta_{2}-\mathrm{N}_{2}\right)\right]$ produced the mixed lanthanum-actinide trimetallic species $\left(\mathrm{C}_{5} \mathrm{Me}_{5}\right)_{2} \mathrm{An}\left[-\mathrm{N}=\mathrm{C}(\mathrm{Bn})\left(\operatorname{tpy}-\mathrm{La}_{2}\left\{\mathrm{C}_{5} \mathrm{Me} \mathrm{H}_{4} \mathrm{H}\right\}_{2}\right)\right]_{2}$ $(\mathrm{An}=\mathrm{Th}(\mathbf{1 0 a}), \mathrm{U}(\mathbf{1 0 b}))$ with evolution of nitrogen gas. As with complexes 7-9, the presence of chemically distinct cyclopentadienyl groups at the different metal ion sites allows for resolution of the metal-metal site disorder in the crystal structure of $\mathbf{1 0 b}$ (vide infra). Development of these three synthetic routes has afforded a series of compounds for study of a variety of metal ions in a redox-active framework. Furthermore, selection of the ions $\mathrm{M}=\mathrm{La}, \mathrm{Sm}, \mathrm{Yb}$ and $\mathrm{U}$ allows for internal comparison of the lanthanides and lanthanum as well as comparison of these elements with uranium.

Representative molecular structures from the X-ray crystal structures of complexes 8, 9a, and 10b are presented in Figures 1-3, respectively, and crystallographic experimental details for complexes $5 \mathbf{a}-\mathbf{b}, \mathbf{6 b}, \mathbf{7 a - b}, \mathbf{8}, \mathbf{9 a}$ and $\mathbf{1 0 b}$ are listed in Table 1 . In all cases, the compounds show Th- $\mathrm{N}_{\text {ketimide }}$ and U-N $\mathrm{N}_{\text {ketimide }}$ bond distances that are consistent with those previously reported for $\mathrm{Th}^{\mathrm{IV}}(2.250(2)-2.286(5) \AA)$ and $\mathrm{U}^{\mathrm{IV}}(2.04(2)-2.225(5) \AA)$ bis(ketimide) complexes (Table 2). $5,6,27,28,30,31$ Across the series of compounds, the Th- $\mathrm{N}_{\text {ketimide }}$ bond distances are greater than those observed for their $\mathrm{U}-\mathrm{N}_{\text {ketimide }}$ analogues, a consequence of the $\sim 0.05 \AA$ larger ionic radius of the $\mathrm{Th}^{\mathrm{IV}}$ ion versus $\mathrm{U}^{\mathrm{IV}}{ }^{35}$ The similarity of the uranium and thorium trimetallic frameworks enables the direct comparison of their electronic properties as a function of metal ion in the terpyridyl wedge. In fact, the greatest variation in bonding parameters between the complexes is found in the M-N $\mathrm{N}_{\text {tpy }}$ bond distances (Table 2). As the charge on the ions within this wedge is also uniform throughout, these distances are functions of ion size and the potential involvement of valence d- and/or f-orbitals in bonding. In comparing the isostructural $U^{\mathrm{III}}-\mathrm{Th}^{\mathrm{IV}}-\mathrm{U}^{\mathrm{III}}$ and $\mathrm{U}^{\mathrm{III}}-\mathrm{U}^{\mathrm{IV}}$ $\mathrm{U}^{\mathrm{III}}$ complexes $\mathbf{7 a - b}$, it was noted that the peripheral $\mathrm{U}-\mathrm{N}_{\text {tpy }}$ distances do not depend on the 
central tetravalent metal ion identity. ${ }^{27}$ This observation allows for a comparison of the structures where $\mathrm{M}=\mathrm{Yb}, \mathrm{U}, \mathrm{Sm}$ and $\mathrm{La}$ when the bridging actinide is either Th or $\mathrm{U}$.

Traversing the complexes where $\mathrm{M}=\mathrm{La}, \mathrm{Sm}$ or $\mathrm{Yb}$, the tpy-wedge bonding parameters are consistent with expectations that the larger $\mathrm{La}^{\mathrm{III}}$ ions $(1.032 \AA$, coordination number $=6)$ exhibit comparatively longer $\mathrm{M}-\mathrm{N}_{\text {tpy }}$ bond distances (La- $\mathrm{N}_{\text {external }}=2.546(9)-2.604(8) \AA$; La- $\mathrm{N}_{\text {internal }}=$ 2.529(8) and 2.536(8) $\AA$ ), while the smaller $\mathrm{Yb}^{\mathrm{III}}$ ions $(0.868 \AA$, coordination number $=6)$ exhibit shorter $\mathrm{M}-\mathrm{N}_{\text {tpy }}$ distances $\left(\mathrm{Yb}-\mathrm{N}_{\text {external }}=2.384(2)-2.467(2) \AA\right.$; $\mathrm{Yb}-\mathrm{N}_{\text {internal }}=2.332(5)-$ 2.382(4) $\AA$ ). The Sm- $\mathrm{N}_{\text {tpy }}$ distances lie intermediate between those values observed for La- $\mathrm{N}_{\text {tpy }}$ and $\mathrm{Yb}-\mathrm{N}_{\text {tpy }}$. Comparing with the structures for $\mathbf{7 a - b}$ where $\mathrm{U}^{\mathrm{III}}$ is contained within the tpy-N wedge reveals $\mathrm{U}-\mathrm{N}_{\text {tpy }}$ distances that are significantly shorter than what would be expected on the basis of ionic radius alone. The radius of the $\mathrm{U}^{\mathrm{III}}$ ion with a coordination number $=6$ is $1.025 \AA$, which is intermediate between the $\mathrm{La}^{\mathrm{III}}$ and $\mathrm{Sm}^{\mathrm{III}}$ radii. However, $\mathrm{U}-\mathrm{N}_{\text {tpy }}$ distances in $\mathbf{7 a - b}$ (U$\mathrm{N}_{\text {external }}=2.442(5)-2.486(5) \AA ; \mathrm{U}-\mathrm{N}_{\text {internal }}=2.323(5)-2.352(5) \AA$ ) are shorter than the La- $\mathrm{N}_{\text {tpy }}(9 \mathbf{a})$ and Sm- $\mathrm{N}_{\mathrm{tpy}}$ (10b) distances. These data provide supporting evidence for a more covalent interaction between the $\mathrm{U}^{\mathrm{III}}$ ions and the tpy-groups in 7a-b than those found in the $4 \mathrm{f}$ congeners. A summary of these bonding differences is shown in the Figure 4. It is clear from this representation that the sizes of the $\mathrm{La}^{\mathrm{III}}, \mathrm{Sm}^{\mathrm{III}}$ and $\mathrm{Yb}^{\mathrm{III}}$ ions in these structures correlates linearly with their $\mathrm{M}^{\mathrm{III}}-\mathrm{N}_{\text {tpy }}$ bond distances, whereas the $\mathrm{U}^{\mathrm{III}}-\mathrm{N}_{\text {tpy }}$ bond distances are significantly shorter than would be expected from purely electrostatic interactions with the tpy“- ligands. Such differences, specifically the presence of 5f/6d-orbitals in uranium for back-bonding with tpy- $\pi^{*}$ orbitals, have been noted previously on comparison of isostructural $\mathrm{Ce}^{\mathrm{III}}$ - and $\mathrm{U}^{\mathrm{III}}$-tpy complexes. $^{2}$ Overall, the structural data establish the similarity of the complexes across a variety of ion types in both the tetravalent and trivalent ion positions. This similarity allows for meaningful comparison between the other types of characterization for the complexes. 
Additionally, the data point to a more covalent interaction between the trivalent uranium ions and the ligand framework than in their $4 \mathrm{f}$ counterparts.

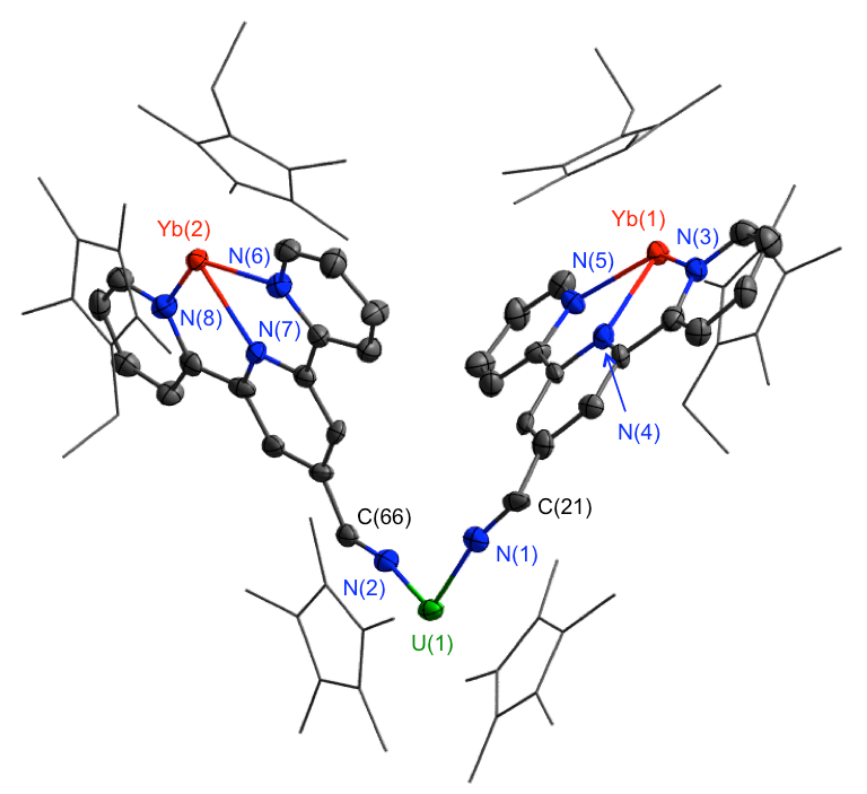

Figure 1. Molecular structure of $\mathbf{8}$ with thermal ellipsoids projected at the $50 \%$ probability level. Hydrogen atoms, benzyl groups and the bonds between cyclopentadienyl ligand centroids and metal centers have been omitted for clarity. Selected bond distances $(\AA)$ : U(1)-N(1) 2.072(6), U(1)-N(2) 2.080(6), $\mathrm{Yb}(1)-\mathrm{N}(3)$ 2.416(6), $\mathrm{Yb}(1)-\mathrm{N}(4)$ 2.332(5), $\mathrm{Yb}(1)-\mathrm{N}(5)$ 2.445(6), $\mathrm{Yb}(2)-\mathrm{N}(6)$ 2.446(6), $\mathrm{Yb}(2)-\mathrm{N}(7)$ 2.345(5), $\mathrm{Yb}(2)-\mathrm{N}(8)$ 2.434(6). 


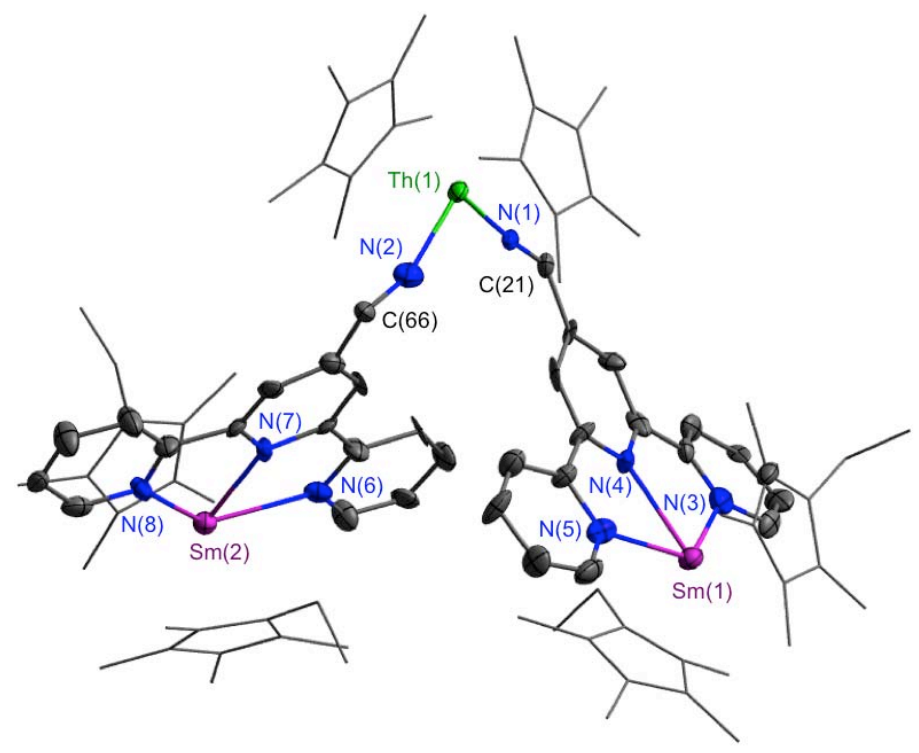

Figure 2. Molecular structure of 9a with thermal ellipsoids projected at the $50 \%$ probability level. Hydrogen atoms, benzyl groups and the bonds between cyclopentadienyl ligand centroids and metal centers have been omitted for clarity. Selected bond distances ( $\AA$ ): Th(1)-N(1) 2.235(11), Th(1)-N(2) 2.244(11), Sm(1)-N(3) 2.544(12), Sm(1)-N(4) 2.436(10), Sm(1)-N(5) 2.540(12), Sm(2)-N(6) 2.500(11), Sm(2)$\mathrm{N}(7)$ 2.440(9), $\mathrm{Sm}(2)-\mathrm{N}(8) 2.490(10)$.

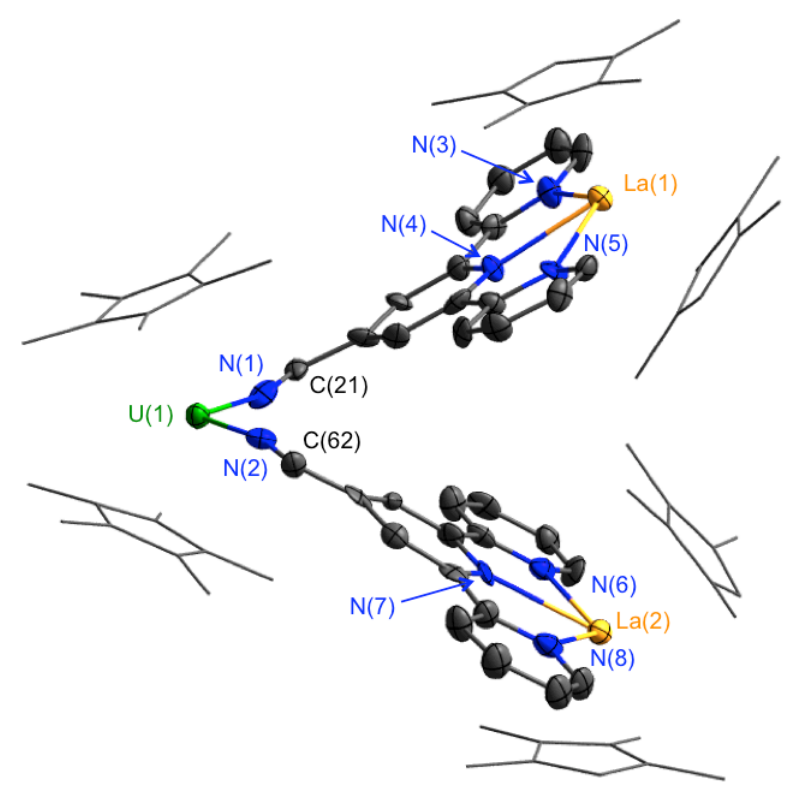

Figure 3. Molecular structure of $\mathbf{1 0 b}$ with thermal ellipsoids projected at the $50 \%$ probability level. Hydrogen atoms, benzyl groups and the bonds between the cyclopentadienyl ligand centroids and metal centers have been omitted for clarity. Selected bond distances $(\AA)$ : U(1)-N(1) 2.057(9), U(1)-N(2) 2.083(9), La(1)-N(3) 2.546(9), La(1)-N(4) 2.536(8), La(1)-N(5) 2.575(8), La(2)-N(6) 2.604(8), La(2)$\mathrm{N}(7)$ 2.529(8), La(2)-N(8) 2.603(9). 
Table 1. Crystallographic Data for 5a-b, 6b, 7a-b, 8, 9a and 10b

\begin{tabular}{|c|c|c|c|c|c|c|c|c|}
\hline & $5 a$ & $5 b \cdot 1 / 2\left(C_{7} H_{8}\right)$ & $6 b$ & $7 \mathrm{a} \cdot \mathrm{O}\left(\mathrm{SiMe}_{3}\right)_{2}$ & $7 \mathbf{b}$ & 8 & $9 a$ & $10 \mathrm{~b} \cdot \mathrm{O}\left(\mathrm{SiMe}_{3}\right)_{2}\left(\mathrm{Et}_{2} \mathrm{O}\right)$ \\
\hline $\begin{array}{l}\text { empirical } \\
\text { formula }\end{array}$ & $\mathrm{C}_{66} \mathrm{H}_{64} \mathrm{~N}_{8} \mathrm{Th}$ & $\mathrm{C}_{69.5} \mathrm{H}_{68} \mathrm{~N}_{8} \mathrm{U}$ & $\mathrm{C}_{113} \mathrm{H}_{132} \mathrm{~N}_{8} \mathrm{UYb}_{2}$ & $\mathrm{C}_{122} \mathrm{H}_{168} \mathrm{~N}_{8} \mathrm{O}_{2} \mathrm{Si}_{4} \mathrm{ThU}_{2}$ & $\mathrm{C}_{110} \mathrm{H}_{129} \mathrm{~N}_{8} \mathrm{U}_{3}$ & $\mathrm{C}_{131} \mathrm{H}_{156} \mathrm{~N}_{8} \mathrm{UYb}_{2}$ & $\mathrm{C}_{114} \mathrm{H}_{142} \mathrm{~N}_{8} \mathrm{OSm}_{2} \mathrm{Th}$ & $\mathrm{C}_{112} \mathrm{H}_{144} \mathrm{La}_{2} \mathrm{~N}_{8} \mathrm{O}_{2} \mathrm{Si}_{2} \mathrm{U}$ \\
\hline $\begin{array}{l}\text { formula } \\
\text { weight }\end{array}$ & 1201.29 & 1207.28 & 2186.38 & 2599.10 & 2277.30 & 2426.75 & 2173.10 & 2206.38 \\
\hline $\begin{array}{l}\text { crystal } \\
\text { system }\end{array}$ & monoclinic & monoclinic & monoclinic & triclinic & triclinic & triclinic & orthorhombic & triclinic \\
\hline$a, \AA$ & $14.624(3)$ & 14.359(3) & $25.246(4)$ & $13.770(3)$ & 13.269(3) & 13.3201(13) & $16.8994(17)$ & $13.4288(14)$ \\
\hline$b, \AA$ & 25.726(5) & 13.611(2) & $9.4223(13)$ & $18.801(4)$ & $17.527(4)$ & 17.9749(18) & 18.7407(19) & $18.774(2)$ \\
\hline$c, \AA$ & 15.592(3) & $28.142(5)$ & $44.649(6)$ & 23.289(5) & 24.493(5) & $24.197(2)$ & 33.271(3) & $21.335(2)$ \\
\hline$a,{ }^{\circ}$ & 90 & 90 & 90 & 81.61(3) & $76.08(3)$ & $104.710(2)$ & 90 & $79.8310(10)$ \\
\hline$\beta,^{\circ}$ & 110.53(3) & 101.815(3) & $93.279(3)$ & $84.69(3)$ & $84.83(3)$ & $92.122(2)$ & 90 & $87.500(2)$ \\
\hline$\gamma,{ }^{\circ}$ & 90 & 90 & 90 & $74.89(3)$ & $86.50(3)$ & $90.266(2)$ & 90 & $75.225(2)$ \\
\hline$V, \AA^{3}$ & 5493.2(19) & 5383.6(17) & 10604(3) & $5749(2)$ & $5502.0(19)$ & $5599.0(10)$ & 10537.2(19) & 5119.2(9) \\
\hline space group & $\mathrm{P} 21 / \mathrm{c}$ & $\mathrm{C} 2 / \mathrm{c}$ & $\mathrm{C} 2 / \mathrm{c}$ & P-1 & P-1 & P-1 & $\mathrm{P} 2{ }_{1} 2_{1} 2_{1}$ & P-1 \\
\hline$Z$ & 4 & 4 & 4 & 2 & 2 & 2 & 4 & 2 \\
\hline$d_{\text {calc }}, \mathrm{g} / \mathrm{cm}^{3}$ & 1.453 & 1.490 & 1.370 & 1.501 & 1.375 & 1.439 & 1.370 & 1.431 \\
\hline $\begin{array}{l}\mu\left(\mathrm{Mo}_{\mathrm{K} \alpha}\right), \\
\mathrm{mm}^{-1}\end{array}$ & 0.71073 & 0.71073 & 0.71073 & 0.71073 & 0.71073 & 0.71073 & 0.71073 & 0.71073 \\
\hline$T, \mathbf{K}$ & $173(2)$ & $141(2)$ & $141(2)$ & $141(2)$ & $141(2)$ & $141(2)$ & $141(2)$ & $120(1)$ \\
\hline $2 \theta_{\text {max }}, \circ$ & 52.02 & 51.44 & 51.36 & 54.18 & 55.10 & 49.54 & 50.88 & 49.90 \\
\hline $\begin{array}{l}\min . / \max . \\
\text { transmission }\end{array}$ & $0.6288 / 0.5022$ & $0.651 / 0.479$ & $0.4565 / 0.9069$ & $0.3075 / 0.7780$ & $0.3807 / 0.8893$ & $0.6666 / 0.7434$ & $0.6287 / 0.9046$ & $0.6375 / 0.9757$ \\
\hline total reflns & 56349 & 25054 & 49343 & 64289 & 63134 & 50448 & 94866 & 47499 \\
\hline unique reflns & 10751 & 5102 & 10028 & 24902 & 24922 & 19041 & 19475 & 17627 \\
\hline parameters & 661 & 339 & 4231 & 1293 & 1119 & 1093 & 12342 & 9090 \\
\hline $\begin{array}{l}R_{1}\left(\mathrm{w} R_{2}\right) \\
(>2 \sigma(\mathrm{I}))\end{array}$ & $\begin{array}{l}0.0610 \\
(0.0948)\end{array}$ & $\begin{array}{l}0.0520 \\
(0.1224)\end{array}$ & $\begin{array}{l}0.0871 \\
(0.2389)\end{array}$ & $\begin{array}{l}0.0518 \\
(0.0856)\end{array}$ & $\begin{array}{l}0.0519 \\
(0.0969)\end{array}$ & $\begin{array}{l}0.0469 \\
(0.1112)\end{array}$ & $\begin{array}{l}0.0671 \\
(0.1283)\end{array}$ & $\begin{array}{l}0.0649 \\
(0.1159)\end{array}$ \\
\hline
\end{tabular}


Table 2. Selected Bond Distances $(\AA)$ and Angles $\left(^{\circ}\right)$ for $\mathbf{5 a - b}, \mathbf{6 b}, \mathbf{7 a - b}, \mathbf{8}, \mathbf{9 a}$ and $\mathbf{1 0 b}$

\begin{tabular}{|c|c|c|c|c|}
\hline Complex & An- $\mathbf{N}_{\text {ket }}$ & $\mathbf{N}_{\text {ket }}=C$ & $A n-N=C$ & $\mathbf{M}-\mathbf{N}_{\text {tpy }}$ \\
\hline \multirow[t]{2}{*}{$5 a$} & Th(1)-N(1) 2.264(6) & $\mathrm{N}(1)-\mathrm{C}(21) 1.265(8)$ & Th(1)-N(1)-C(21) 170.9(5) & \multirow[t]{2}{*}{ N/A } \\
\hline & Th(1)-N(2) 2.270(6) & $\mathrm{N}(2)-\mathrm{C}(44) 1.271(8)$ & $\operatorname{Th}(1)-\mathrm{N}(2)-\mathrm{C}(44) 165.6(5)$ & \\
\hline $5 \mathbf{b}$ & $\mathrm{U}(1)-\mathrm{N}(1) 2.206(6)$ & $\mathrm{N}(1)-\mathrm{C}(11)$ 1.262(9) & $\mathrm{U}(1)-\mathrm{N}(1)-\mathrm{C}(11) \quad 164.6(5)$ & N/A \\
\hline \multirow[t]{6}{*}{$6 \mathbf{b}$} & $\mathrm{U}(1)-\mathrm{N}(7) 2.054(8)$ & $\mathrm{N}(7)-\mathrm{C}(64)$ 1.369(11) & $\mathrm{U}(1)-\mathrm{N}(7)-\mathrm{C}(64)$ 168.7(7) & $\mathrm{Yb}(1)-\mathrm{N}(4) 2.384(2)$ \\
\hline & U(1)-N(8) 2.135(8) & $\mathrm{N}(8)-\mathrm{C}(21) 1.313(11)$ & U(1)-N(8)-C(21) 168.4(7) & $\mathrm{Yb}(1)-\mathrm{N}(5) 2.357(4)$ \\
\hline & & & & $\mathrm{Yb}(1)-\mathrm{N}(6)$ 2.414(4) \\
\hline & & & & $\mathrm{Yb}(2)-\mathrm{N}(1) 2.467(2)$ \\
\hline & & & & $\mathrm{Yb}(2)-\mathrm{N}(2)$ 2.382(4) \\
\hline & & & & $\mathrm{Yb}(2)-\mathrm{N}(3)$ 2.430(7) \\
\hline \multirow[t]{6}{*}{$7 a$} & Th(1)-N(2) 2.247(5) & $\mathrm{N}(1)-\mathrm{C}(21) 1.274(8)$ & Th(1)-N(1)-C(21) 165.6(5) & U(1)-N(3) 2.460(5) \\
\hline & Th(1)-N(1) 2.239(5) & $\mathrm{N}(2)-\mathrm{C}(66) 1.285(7)$ & Th(1)-N(2)-C(66) 165.0(4) & $\mathrm{U}(1)-\mathrm{N}(4) 2.323(5)$ \\
\hline & & & & $\mathrm{U}(1)-\mathrm{N}(5) 2.454(5)$ \\
\hline & & & & $\mathrm{U}(2)-\mathrm{N}(6) 2.486(5)$ \\
\hline & & & & U(2)-N(7) 2.339(5) \\
\hline & & & & $\mathrm{U}(2)-\mathrm{N}(8) 2.442(5)$ \\
\hline \multirow[t]{6}{*}{$7 \mathbf{b}$} & $\mathrm{U}(1)-\mathrm{N}(1) 2.162(6)$ & $\mathrm{N}(1)-\mathrm{C}(21) 1.274(8)$ & U(1)-N(1)-C(21) 167.6(5) & $\mathrm{U}(2)-\mathrm{N}(3) 2.454(6)$ \\
\hline & $\mathrm{U}(1)-\mathrm{N}(2) 2.159(6)$ & $\mathrm{N}(2)-\mathrm{C}(66) 1.284(8)$ & U(1)-N(2)-C(66) 167.0(5) & $\mathrm{U}(2)-\mathrm{N}(4) 2.352(5)$ \\
\hline & & & & $\mathrm{U}(2)-\mathrm{N}(5) 2.460(5)$ \\
\hline & & & & $\mathrm{U}(3)-\mathrm{N}(6) 2.472(5)$ \\
\hline & & & & $\mathrm{U}(3)-\mathrm{N}(7) 2.351(5)$ \\
\hline & & & & $\mathrm{U}(3)-\mathrm{N}(8) 2.444(5)$ \\
\hline \multirow[t]{6}{*}{8} & $\mathrm{U}(1)-\mathrm{N}(1) 2.072(6)$ & N(1)-C(21) 1.337(9) & U(1)-N(1)-C(21) 168.3(5) & $\mathrm{Yb}(1)-\mathrm{N}(3)$ 2.416(6) \\
\hline & $\mathrm{U}(1)-\mathrm{N}(2) 2.080(6)$ & $\mathrm{N}(2)-\mathrm{C}(66) 1.346(9)$ & U(1)-N(2)-C(66) 168.6(5) & $\mathrm{Yb}(1)-\mathrm{N}(4)$ 2.332(5) \\
\hline & & & & $\mathrm{Yb}(1)-\mathrm{N}(5)$ 2.445(6) \\
\hline & & & & $\mathrm{Yb}(2)-\mathrm{N}(6) 2.446(6)$ \\
\hline & & & & $\mathrm{Yb}(2)-\mathrm{N}(7) 2.345(5)$ \\
\hline & & & & $\mathrm{Yb}(2)-\mathrm{N}(8) 2.434(6)$ \\
\hline \multirow[t]{6}{*}{ 9a } & $\operatorname{Th}(1)-\mathrm{N}(1) 2.235(11)$ & $\mathrm{N}(1)-\mathrm{C}(21) 1.275(16)$ & Th(1)-N(1)-C(21) 174.2(9) & $\operatorname{Sm}(1)-N(3) 2.544(12)$ \\
\hline & $\operatorname{Th}(1)-\mathrm{N}(2) 2.244(11)$ & $\mathrm{N}(2)-\mathrm{C}(66) 1.251(16)$ & Th(1)-N(2)-C(66) 161.3(10) & $\operatorname{Sm}(1)-N(4) 2.436(10)$ \\
\hline & & & & $\mathrm{Sm}(1)-\mathrm{N}(5) 2.540(12)$ \\
\hline & & & & $\operatorname{Sm}(2)-N(6) 2.500(11)$ \\
\hline & & & & $\operatorname{Sm}(2)-N(7) 2.440(9)$ \\
\hline & & & & $\operatorname{Sm}(2)-N(8) 2.490(10)$ \\
\hline \multirow[t]{6}{*}{ 10b } & $\mathrm{U}(1)-\mathrm{N}(1) 2.057(9)$ & N(1)-C(21) 1.316(12) & U(1)-N(1)-C(21) 167.5(7) & La(1)-N(3) 2.546(9) \\
\hline & $\mathrm{U}(1)-\mathrm{N}(2) 2.083(9)$ & $\mathrm{N}(2)-\mathrm{C}(62) 1.313(12)$ & U(1)-N(2)-C(62) 168.2(7) & La(1)-N(4) 2.536(8) \\
\hline & & & & $\mathrm{La}(1)-\mathrm{N}(5) 2.575(8)$ \\
\hline & & & & La(2)-N(6) 2.604(8) \\
\hline & & & & $\mathrm{La}(2)-\mathrm{N}(7) 2.529(8)$ \\
\hline & & & & La(2)-N(8) 2.603(9) \\
\hline
\end{tabular}




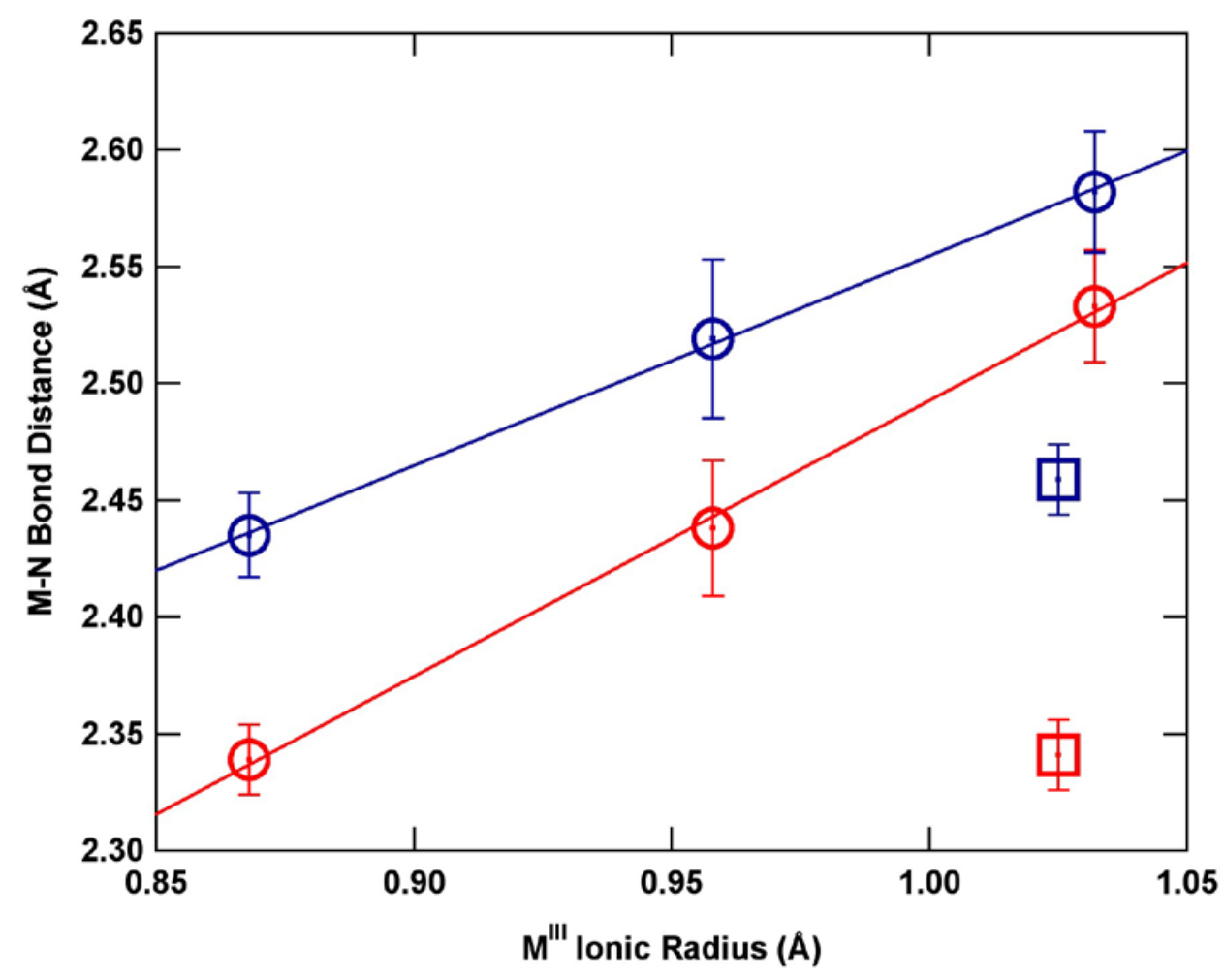

Figure 4. Summary of the $\mathrm{M}^{\mathrm{III}}-\mathrm{N}$ bond distances for $\mathbf{7 a - b}, \mathbf{8}, \mathbf{9 a}$, and $\mathbf{1 0 b}$. The average $\mathrm{M}^{\mathrm{III}}-\mathrm{N}_{\text {external }}$ distances are shown in red while average $\mathrm{M}^{\mathrm{III}}-\mathrm{N}_{\text {internal }}$ distances are in blue. Error bars represent $3 \sigma$ for given distances. The deviation from the linear correlation for the $\mathrm{U}^{\mathrm{III}}$ complex (square data points) indicates an enhanced covalency in the bonding of the tpy"- moiety with that ion.

Electrochemistry. Electrochemical data have much to offer for assessment of electronic interactions between structurally equivalent redox centers and relative stabilities of mixed-valent configurations in the homo- and heterotrimetallic complexes elucidated in this study. Notably, our studies of these multimetallic f-element metallocenes have been conducted under nearly identical experimental (solvent/electrolyte) conditions to avoid introduction of matrix-dependent effects on the separations between voltammetric waves. $^{36,37}$ In previous reports, complexes $\mathbf{5 a - b}$ as well as $\left(\mathrm{C}_{5} \mathrm{Me}_{5}\right)_{2} \mathrm{Yb}$ (tpy) (11) and $\left(\mathrm{C}_{5} \mathrm{Me}_{5}\right)_{2} \mathrm{U}($ tpy) (12) were analyzed for comparison with the multimetallic complexes $\mathbf{6 a - b}$ and $\mathbf{7 a - b} .^{25,27,38}$ Complexes $\mathbf{5 a - b}$ showed noteworthy voltammetric responses themselves. As presented in Figure 5, complex 5a displays a set of two quasi-reversible waves at -2.42 and $-2.63 \mathrm{~V}$, which were assigned to successive reductions of the tpy moieties in this system. No thorium-based processes are expected for $\mathbf{5 a}$ or any of the $\mathrm{Th}^{\mathrm{IV}}$ complexes reported here as a 
consequence of the $6 \mathrm{~d}^{0} 5 \mathrm{f}^{0}$ electronic configuration and orbital energies that place these metal-based redox processes outside the solvent window of these experiments. Data for the uranium analogue $\mathbf{5 b}$ is also given in the Figure 5, and is similar to $\mathbf{5 a}$ with the addition of two new redox processes at -0.38 and $-2.42 \mathrm{~V}$. These waves were assigned to $\mathrm{U}^{\mathrm{V} / \mathrm{IV}}$ and $\mathrm{U}^{\mathrm{IV} / \mathrm{III}}$ redox couples, consistent with benchmark data reported for uranium(IV) bis(ketimide) complexes. ${ }^{29,30}$ Square-wave voltammetry affords clear resolution of the three reduction waves observed for $5 \mathbf{b}$ between -2.00 and $-2.75 \mathrm{~V}$ and assignment of the wave at -2.42 to the $\mathrm{U}^{\mathrm{IV} / \mathrm{III}}$ couple can be made definitively by noting the separation $\left(\Delta \mathrm{E}_{1 / 2}=2.04 \mathrm{~V}\right)$ between the $\mathrm{U}^{\mathrm{V} / \mathrm{IV}}$ and $\mathrm{U}^{\mathrm{IV} / \mathrm{III}}$ waves, which is consistent with the difference between the metal waves across a large number of reported uranium(IV) metallocene complexes..$^{29,30}$

The appearance of two, well-resolved tpy-based reduction waves in 5a separated by $210 \mathrm{mV}$ indicates step-wise reduction of these groups and substantial electronic interaction between them in this complex. $^{39}$ The uranium analogue $\mathbf{5 b}$ also exhibits significant separation of the tpy-group reduction waves; however, the presence of a $\mathrm{U}^{\mathrm{IV} / \mathrm{III}}$ reduction sandwiched between the tpy-reduction processes precludes direct comparison of the extent of electronic interaction between the tpy moieties in 5a versus 5b. The appearance of the intervening metal-based waves indicates the complex exists in a nominal UIII configuration before the second tpy-based reduction occurs.

Coordination of additional lanthanide or uranium metallocene moieties to the tpy sites of $\mathbf{5 a - b}$ was expected to introduce additional redox activity in these complexes, particularly in light of the voltammetry of $\left(\mathrm{C}_{5} \mathrm{Me}_{5}\right)_{2} \mathrm{Yb}$ (tpy) (11), which exhibits a tpy-based oxidation and a Yb-based reduction wave (Figure 5). In fact, our initial report on the mixed-metal $\mathrm{Yb}^{\mathrm{III}}-\mathrm{Th}^{\mathrm{IV}}-\mathrm{Yb}^{\mathrm{III}}$ and $\mathrm{Yb}^{\mathrm{III}}-\mathrm{U}^{\mathrm{IV}}-\mathrm{Yb}^{\mathrm{III}}$ complexes 6a-b demonstrated a larger than expected number of redox events present in the compounds, ${ }^{25}$ observations which were sample independent thereby alleviating concerns over sample purity. Assignment of these waves was made on the basis of the extant data suggesting the presence of multiple Yb-tpy redox-isomers. However, subsequent investigations revealed redox-isomerism is not a contributing factor to the ground state electronic structures of these and related complexes. ${ }^{33}$ 


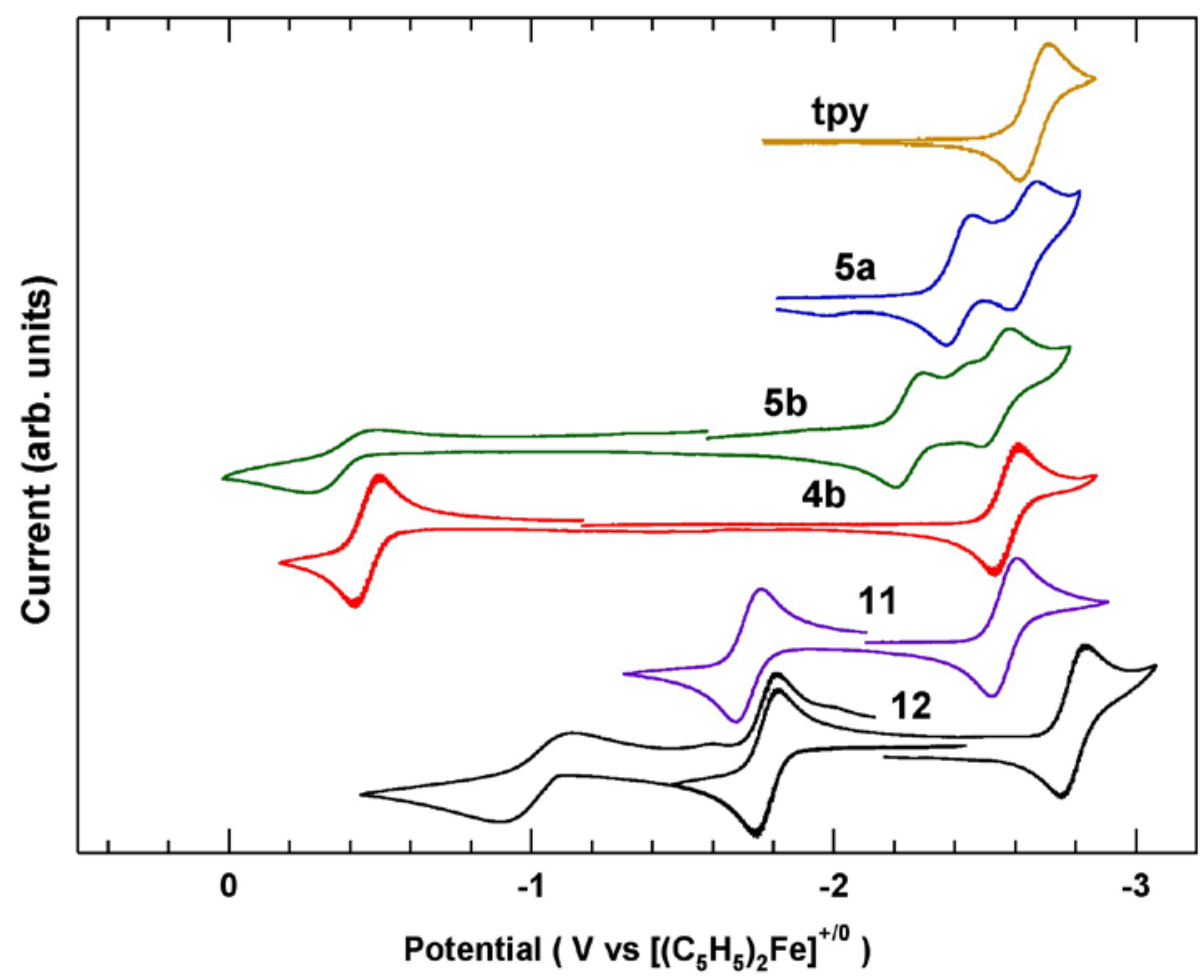

Figure 5. Cyclic voltammograms for precursor free ligand (2,2':6',2"-terpyridine; tpy) and complexes $\mathbf{4 b}$, $\mathbf{5 a - b}, \mathbf{1 1}$, and 12 in $\sim 0.1 \mathrm{M}\left[\mathrm{Bu}_{4} \mathrm{~N}\right][$ fluoroarylborate]/THF solution at $200 \mathrm{mV} / \mathrm{s}$ scan rate.

As discussed above, the synthesis of $\left(\mathrm{C}_{5} \mathrm{Me}_{5}\right)_{2} \mathrm{U}\left[-\mathrm{N}=\mathrm{C}(\mathrm{Bn})\left(\operatorname{tpy}-\mathrm{Yb}\left\{\mathrm{C}_{5} \mathrm{Me}_{4} \mathrm{Et}\right\}_{2}\right)\right]_{2}$ (8) provides a superior compound compared to $\mathbf{6 b}$ in terms of crystallographic resolution of the metal ion sites. Electrochemical evaluation of this material provided a striking result. The voltammogram is simplified considerably compared to that of $\mathbf{6 b}$, showing well-behaved reversible redox processes, and generally simpler assignments/evaluations of these processes (Figure 6A). Comparison of the waves observed for 8 at $-1.35 \mathrm{~V},-1.50 \mathrm{~V},-2.21$ and $-2.71 \mathrm{~V}$ with those for $\left(\mathrm{C}_{5} \mathrm{Me}_{5}\right)_{2} \mathrm{Yb}($ tpy) $(-1.72$ and $-2.56 \mathrm{~V}$, Figure 5) afforded assignment of the more positive set of two as tpy"/tpy ${ }^{0}$ oxidations and the more negative set as $\mathrm{Yb}^{\mathrm{III}} / \mathrm{Yb}^{\mathrm{II}}$ reductions. The tpy ${ }^{-1} / \mathrm{tpy}^{0}$ oxidation potentials are split by $150 \mathrm{mV}$, indicating definite electronic interaction between these sites. Interestingly, the wave splitting for the ytterbium-based set, $0.50 \mathrm{~V}$, is significantly larger than that for the ligand-based set. The strength of this $\mathrm{Yb}-\mathrm{Yb}$ interaction is on par with that seen in $\left[\left\{\left(\mathrm{C}_{5} \mathrm{Me}_{5}\right)_{2} \mathrm{Yb}\right\}_{2}(\mu\right.$-tppz) $]$ (13; tppz $=$ 2,3,5,6-tetrakis(2-pyridyl)pyrazine) with a $0.60 \mathrm{~V}$ wave separation, despite the much larger through-bond $\mathrm{Yb} \cdots \mathrm{Yb}$ distance in 8 ( $\sim 22.7 \AA$ ) versus 
that in $13(\sim 7.6 \AA)^{40,41}$ A calculated comproportionation constant of $K_{c} \approx 10^{8.5}$ from this wave spacing illustrates the stability of the singly reduced species $[\mathbf{8}]^{-16}$ Evaluation of complexes where $\mathrm{M}=\mathrm{Sm}$ or La (Scheme 1) provided additional observations. Where the central actinide is uranium, the electrochemical waves observed for 8 remain present for both $M=\operatorname{Sm}(\mathbf{9 b})$ and La (10b) with negligible variation in wave potentials or splittings depending on the identity of M (Figure 6A and Table 3). This is consistent with observed and nearly identical redox behavior for the monometallic complexes, $\left(\mathrm{C}_{5} \mathrm{Me}_{5}\right)_{2} \mathrm{Yb}$ (tpy) (11) and $\left(\mathrm{C}_{5} \mathrm{Me}_{5}\right)_{2} \mathrm{Sm}\left(\right.$ tpy) (14), ${ }^{33}$ and demonstrates that the $\left(\mathrm{C}_{5} \mathrm{Me}_{4} \mathrm{H}\right)^{-}$supporting ligand for 10a-b also yields complexes stable against decomposition on the voltammetric time scale. It is striking, given the through-bond $\mathrm{Ln} \cdots \mathrm{Ln}$ distances and $4 \mathrm{f}-5 \mathrm{f}-4 \mathrm{f}$ orbitals involved in complexes $\mathbf{8}, \mathbf{9 b}$ and 10b, that the coupling is so strong, slightly larger than the benchmark Creutz-Taube ion. ${ }^{16}$ The large Ln-Ln interaction reflected in this splitting is attributed in part to the population of the $\pi^{*}$ orbitals on the bridging tpy-ketimide ligands. A similar large effect has been reported for a range of bimetallic ytterbocene and samarocene complexes of bridging polypyridyl ligands where in all cases the ligand bridge is in either a dianion or diradical reduced state. ${ }^{40}$ Attribution of the larger interaction between the metal centers to the $\pi^{*}$ electron population is based on comparison to the structurally analogous bimetallic ruthenium complexes for which the bridging polypyridyl ligand is not reduced, and for which the separation of the metal-based oxidation waves is only $0.30 \mathrm{~V}$ for the tppz bridged system, and becomes zero for larger metal $\cdots$ metal separation. ${ }^{42,43}$

For the thorium-bridged complexes $(\mathrm{M}=\mathrm{Sm}(\mathbf{9 a})$ and La (10a)) significant changes are seen in their electrochemical behavior compared to the uranium analogues (9b and $\mathbf{1 0 b}$ ), as well as changes with respect to each other (9a versus 10a; Figure 6A and Table 3). The tpy ${ }^{-} /$tpy $^{0}$ oxidation waves for 9a and 10a, split by 110 and $130 \mathrm{mV}$, respectively, show a smaller difference 


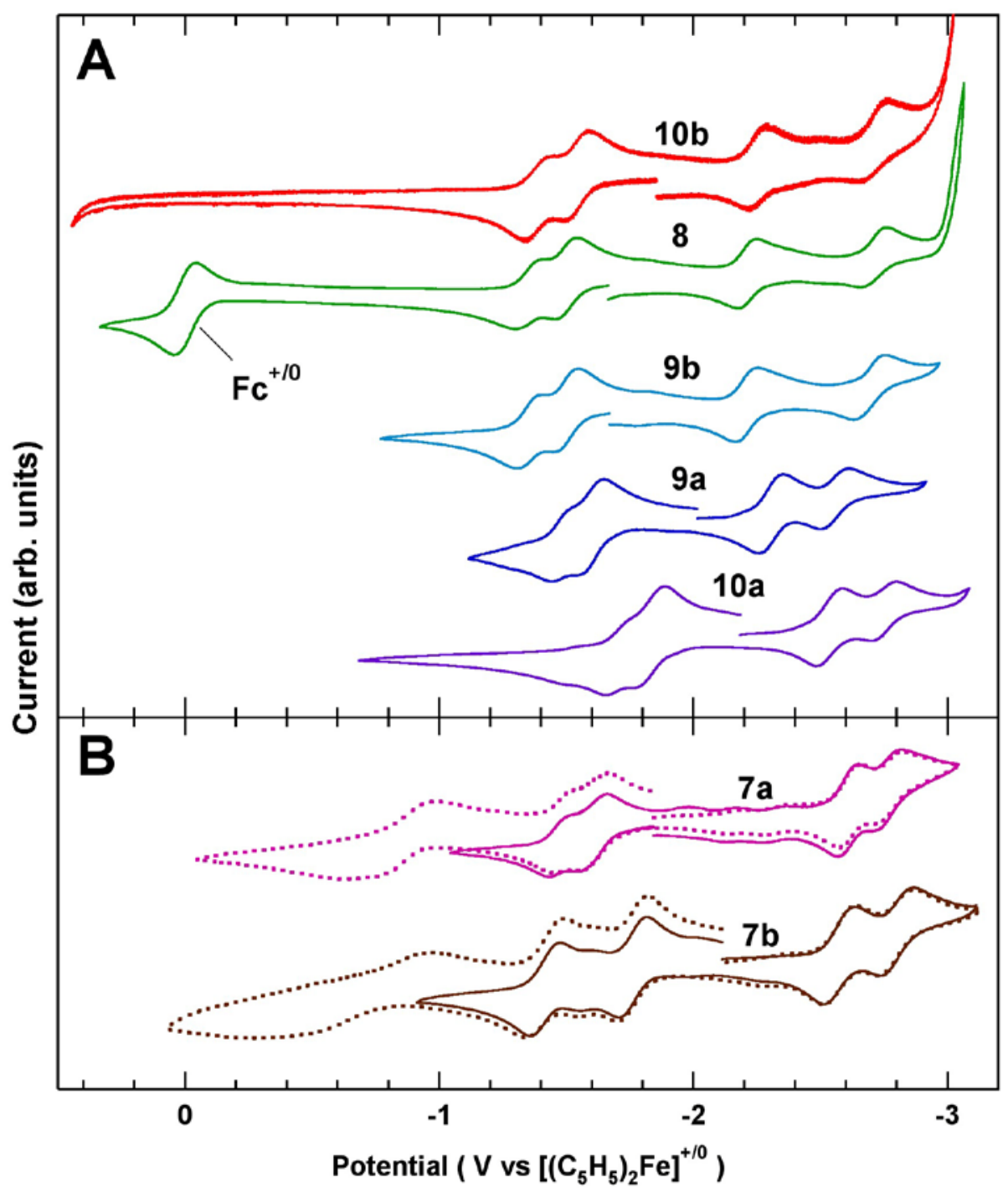

Figure 6. Cyclic voltammograms for (A) 4f-5f-4f trimetallic complexes 8, 9a-b, 10a-b and (B) 5f-5f-5f trimetallic complexes 7a-b in $\sim 0.1 \mathrm{M}\left[\mathrm{Bu}_{4} \mathrm{~N}\right]$ [fluoroarylborate]/THF solution at $200 \mathrm{mV} / \mathrm{s}$ scan rate. The dashed lines in (B) obtained for scans to more anodic potentials illustrate that the peripheral $\mathrm{U}^{\mathrm{III}}$ oxidation waves, while poorly resolved, do not influence the reversibility of the other redox processes.

between the two processes than for the uranium complexes $\mathbf{9 b}$ and $\mathbf{1 0 b}$. This indicates the $\mathrm{Th}^{\mathrm{IV}}$ ion is a poorer conduit for electronic communication between tpy groups. The $\Delta E_{1 / 2}$ between the metal reduction waves in 9a and 10a are 0.26 and $0.22 \mathrm{~V}$, respectively, approximately half the values observed for the uranium analogues. Evaluating comproportionation constants for [9a] ${ }^{-}$and [10a] yields $K_{c} \approx$ $10^{4.4}$ and $10^{3.7}$ respectively, indicating a $\sim 10^{4}$-fold greater stability of the monoanionic uranium(IV) complexes over the thorium(IV) ones.

The sum of these data for the $4 \mathrm{f}-5 \mathrm{f}-4 \mathrm{f}$ systems indicates that there are two principal factors in dictating the magnitude of the electronic coupling interaction between corresponding $\operatorname{tpy}^{0} / \mathrm{tpy}^{\bullet-}$ or 
$\mathrm{Ln}^{\mathrm{III}} / \mathrm{Ln}^{\mathrm{II}}$ redox centers. The first is the occupancy of $\pi^{*}$ orbitals on the ligand bridges as noted above.

The second, more interesting factor is the identity of the bridging actinide ion. Inasmuch as there are only minor differences in the structural parameters between the $\mathrm{Th}^{\mathrm{IV}}$ and $\mathrm{U}^{\mathrm{IV}}$ congeners, this effect clearly implicates the role of 5f- and 6d-orbital participation from the actinide ion in enhancing communication between the peripheral lanthanide metal centers. This observation is consistent with our studies of monometallic $\left(\mathrm{C}_{5} \mathrm{Me}_{5}\right)_{2} \mathrm{An}^{\mathrm{IV}}(\mathrm{An}=\mathrm{Th}$ and $\mathrm{U})$ ketimide complexes in which the participation of the metal 5f-orbitals in metal-ketimide bonding is clearly manifest in both spectroscopic and electrochemical properties and is greater for uranium than thorium. ${ }^{7,8,29-31}$ The role of the bridging actinide moiety in enhancing communication in these heterotrimetallic systems is acutely illustrated by comparison to the behavior of the structurally analogous $\left\{\left(\mathrm{C}_{5} \mathrm{Me}_{5}\right)_{2} \mathrm{Yb}\right\}_{2}\left(\mu-1-\mathrm{Me}-3,5-\mathrm{tpy}_{2}-\mathrm{C}_{6} \mathrm{H}_{2}\right)$ (15) system in which the $\left(\mathrm{C}_{5} \mathrm{Me}_{5}\right)_{2} \mathrm{An}$ (ketimide $)_{2}$ bridge is replaced with a simple phenyl bridge. This latter system, even with occupied $\pi^{*}$ orbitals on the tpy moieties, shows no measurable splitting of the lanthanide-based reduction waves. $^{41}$

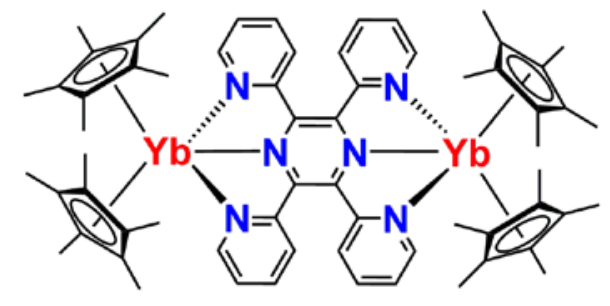

13

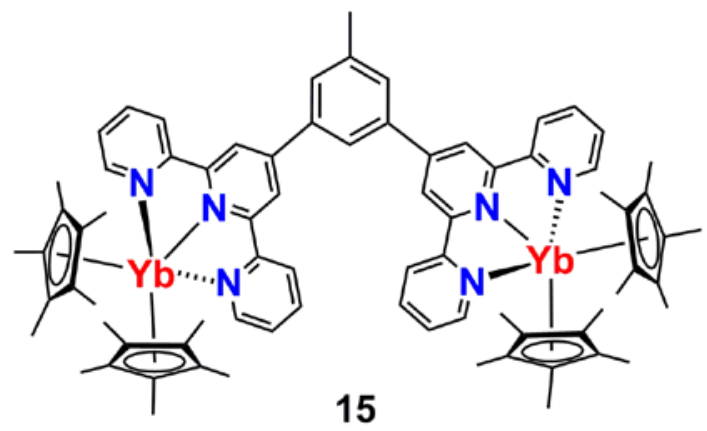

15

Comparison of the lanthanum and lanthanide congeners with the heterotrimetallic $\mathrm{U}^{\mathrm{III}}-\mathrm{Th}^{\mathrm{IV}}-\mathrm{U}^{\mathrm{III}}$ complex 7a and homotrimetallic $U^{\mathrm{III}}-\mathrm{U}^{\mathrm{IV}}-\mathrm{U}^{\mathrm{III}}$ complex $\mathbf{7 b}$ allows for assessment of the $4 f-5 f-4 f$ vs. 5f-5f5f mixed-valencies. As shown in Figure 6B, differences between these systems are immediately apparent on evaluation of their cyclic voltammograms. For 7a-b, the two most negative oxidation waves are still ascribed to tpy ${ }^{-} /$tpy $^{0}$ processes and appear at approximately the same potential as in the other trimetallic systems. However, the observed reduction waves are attributed to tpy ${ }^{-} /$tpy $^{2-}$ processes $^{2}$ for these systems. ${ }^{27}$ The peripheral metal "M"-based redox processes are now oxidative $\mathrm{U}^{\mathrm{III}} / \mathrm{U}^{\mathrm{IV}}$, and are 
shifted by $\sim+1.5 \mathrm{~V}$ relative to the potential for the $\mathrm{U}^{\mathrm{IV}} / \mathrm{U}^{\mathrm{III}}$ couple in $5 \mathbf{b}$. Furthermore, these uranium(III) oxidation waves are quasi-reversible, and significantly broadened compared to other redox processes for these compounds. This indicates that the electron-transfer kinetics for the " $\mathrm{M}$ " metal ion redox processes are significantly different for the $4 \mathrm{f}$ ions (and lanthanum) than for uranium. Square-wave voltammetry affords deconvolution of these broad oxidation waves at $\sim-0.8 \mathrm{~V}$ in $\mathbf{7 a - b}$ into the expected two resolvable processes each. The broad nature of these waves does not allow for precise determination of the potentials for each of the processes; however, estimates for the $\mathrm{U}^{\mathrm{III}}$ oxidation waves from the square-wave experiments are listed in the Table 3 . The wave separation $\Delta E_{1 / 2}$ for the $U^{\mathrm{III}}$ oxidations are $\sim 0.19$ and $\sim 0.31 \mathrm{~V}$ for $\mathbf{7 a}$ and $\mathbf{7 b}$, respectively. Given the expected larger overlap of the $5 f$ orbitals of $U^{\text {III }}$ than the $4 \mathrm{f}$ orbitals of the $\mathrm{Ln}^{\mathrm{III}}$ systems with the peripheral tpy ligands, these separations are unexpectedly smaller than in the $4 \mathrm{f}$ congeners. However, these metal-based waves in 7a-b occur after having first removed all the $\pi^{*}$ electrons from the tpy moieties. As noted above, occupation of the ligand $\pi^{*}$ orbitals clearly induces greater electronic coupling between the peripheral "M" centers. Indirect evidence for larger participation of uranium(III) valence orbitals than in the $4 \mathrm{f}$ congeners can be found in these data. The appearance of tpy ${ }^{-} / \mathrm{tpy}^{2-}$ reduction waves at $\sim-2.8 \mathrm{~V}$ in $7 \mathbf{a}$ and 7b indicates an overall larger stabilization of ketimide-tpy $\pi^{*}$ orbitals than in any of the other $4 \mathrm{f}$ or lanthanum complexes. Comparing complexes $\mathbf{7 b}$ and $\mathbf{1 0 b}$, the ionic radius for $\mathrm{U}^{\mathrm{III}}$ (coordination number = 6) is $1.025 \AA$; whereas $\mathrm{La}^{\mathrm{III}}$ is $1.032 \AA$ (vide supra). ${ }^{35}$ Given their similar sizes, the stabilization of the tpy-/tpy ${ }^{2-}$ reduction waves must be the result of the greater interaction between the ligand $\pi^{*}$ orbitals and the $5 f$ valence orbitals for $\mathbf{7 b}$ through $\pi$ back-bonding as noted above. ${ }^{2}$

A final comment is warranted on the voltammetric behavior of these trimetallic complexes. For those systems containing a $\mathrm{U}^{\mathrm{IV}}$ ion in the bridging position, one would anticipate redox activity for this ion similar to that seen for $\mathbf{5 b}$; namely, both oxidation $\mathrm{U}^{\mathrm{IV}} / \mathrm{U}^{\mathrm{V}}$ and reduction $\mathrm{U}^{\mathrm{IV}} / \mathrm{U}^{\mathrm{III}}$ waves. Evidence for either oxidation or reduction waves associated with the monometallic uranium(IV) bis(ketimide) 
Table 3. Summary of Voltammetric Data for Precursor and Trimetallic $\left(\mathrm{C}_{5} \mathrm{Me}_{5}\right)_{2} \mathrm{An}\left[-\mathrm{N}=\mathrm{C}(\mathrm{Bn})\left(\operatorname{tpy}-\mathrm{M}\left\{\mathrm{C}_{5} \mathrm{Me}_{4} \mathrm{R}\right\}_{2}\right)\right]_{2}$ Complexes

\section{Redox Process ${ }^{\text {a }}$}

Ligand-based

Peripheral "M"-based

Ref.

\begin{tabular}{llllll}
\hline$E_{1 / 2}(1)$ & $E_{1 / 2}(2)$ & $\left|\Delta E_{1 / 2}\right|$ & & $E_{1 / 2}(1)$ & $E_{1 / 2}(2)$
\end{tabular}

Precursors

\begin{tabular}{|c|c|c|c|c|c|c|c|}
\hline tpy & -2.66 & & & & & & 41 \\
\hline $5 a$ & -2.42 & -2.63 & 0.21 & & & & 25 \\
\hline $5 \mathbf{b}$ & -2.25 & -2.53 & 0.28 & & & & 25 \\
\hline 11 & -1.72 & & & -2.56 & & & 41 \\
\hline$\left(\mathrm{C}_{5} \mathrm{Me}_{5}\right)_{2} \mathrm{Sm}$ (tpy) & -1.74 & & & -2.55 & & & 33 \\
\hline \multirow[t]{2}{*}{12} & -1.74 & & & -0.98 & & & 27 \\
\hline & -2.75 & & & & & & \\
\hline \multicolumn{8}{|l|}{$4 f-5 f-4 f$} \\
\hline 8 & -1.35 & -1.50 & 0.15 & -2.21 & -2.71 & 0.50 & This work \\
\hline 9a & -1.48 & -1.59 & 0.11 & -2.29 & -2.55 & 0.26 & This work \\
\hline $9 b$ & -1.36 & -1.51 & 0.15 & -2.21 & -2.71 & 0.50 & This work \\
\hline $10 a^{b}$ & -1.69 & -1.82 & 0.13 & -2.55 & -2.77 & 0.22 & This work \\
\hline $10 b^{b}$ & -1.37 & -1.52 & 0.15 & -2.24 & -2.71 & 0.47 & This work \\
\hline \multicolumn{8}{|l|}{$5 f-5 f-5 f$} \\
\hline \multirow[t]{2}{*}{$7 a$} & -1.47 & -1.61 & 0.14 & -0.70 & -0.86 & 0.16 & 27 \\
\hline & -2.61 & -2.78 & 0.17 & & & & \\
\hline \multirow[t]{2}{*}{$7 \mathbf{b}$} & -1.41 & -1.76 & 0.25 & -0.48 & -0.79 & 0.31 & 27 \\
\hline & -2.58 & -2.80 & 0.22 & & & & \\
\hline
\end{tabular}

${ }^{\mathrm{a}}$ Half-wave potentials are in volts vs. $\left[\left(\mathrm{C}_{5} \mathrm{H}_{5}\right)_{2} \mathrm{Fe}\right]^{+/ 0}$ in $\sim 0.1 \mathrm{M}\left[\mathrm{Bu}_{4} \mathrm{~N}\right]\left[\mathrm{B}\left(\mathrm{C}_{6} \mathrm{~F}_{5}\right)_{4}\right] / \mathrm{THF}$ unless otherwise noted. All $\Delta \mathrm{E}_{1 / 2}$ values are in volts. ${ }^{\mathbf{b}}$ Electrolyte for these systems was $\sim 0.1 \mathrm{M}\left[\mathrm{Bu}_{4} \mathrm{~N}\right]\left[\mathrm{B}\left\{3,5-\left(\mathrm{CF}_{3}\right)_{2}-\mathrm{C}_{6} \mathrm{H}_{3}\right\}_{4}\right]$. 
complexes are not observed in any of the trimetallic systems. The redox energetics of the active metals in these systems have been found to be significantly perturbed by the existence of electrons in the $\pi^{*}$ orbitals in the ketimide-tpy linkages, and this effect would certainly carry over to the bridging $\mathrm{U}^{\mathrm{IV}}$ ion. This added electron density should result in shifts of both $\mathrm{U}^{\mathrm{IV}}$-based oxidation and reduction processes to more negative potentials, and could conceivably shift the reduction process outside of the accessible potential window. However, the absence of discernible $\mathrm{U}^{\mathrm{IV}}$ redox waves in these complexes remains unresolved.

X-Ray Absorption Spectroscopy. Hard and soft X-ray absorption studies have become premier tools for the studies of actinides both from a practical standpoint in the study of immobilized wasteforms and environmental speciation, ${ }^{44,45}$ as well as fundamental studies of f-electron localization/delocalization in materials and metal-ligand covalency in complexes. ${ }^{46-48}$ Direct detection of uranium oxidation states using $L_{\mathrm{III}}$-edge X-ray Absorption Near Edge Spectroscopy (XANES) is a central aspect of this work; however, very little valence $L_{\mathrm{III}}$-edge chemical shift information for uranium organometallic complexes has appeared in the literature. $^{49-51}$ In a series of isostructural uranium complexes, Meyer anecdotally reported negligible shifts for $L_{\mathrm{III}}$-edge energies with oxidation state. ${ }^{50}$ In this context we sought to measure $L_{\mathrm{III}}$-edge energies on a series of well-defined organometallic uranium complexes to evaluate the potential for oxidation state assignment.

The complexes $\left(\mathrm{C}_{5} \mathrm{Me}_{4} \mathrm{Et}\right)_{2} \mathrm{U}(\mathrm{tpy})(\mathbf{1 2}),\left(\mathrm{C}_{5} \mathrm{Me}_{5}\right)_{2} \mathrm{U}[-\mathrm{N}=\mathrm{C}(\mathrm{Bn})(\mathrm{tpy})]_{2}(5 \mathbf{b})$, and $\left(\mathrm{C}_{5} \mathrm{Me}\right)_{5} \mathrm{U}(=\mathrm{N}-2,6-$ $\left.{ }^{i} \mathrm{Pr}_{2}-\mathrm{C}_{6} \mathrm{H}_{3}\right)(\mathrm{I})$ (16) were measured to serve as chemical shift standards for canonical, organometallic $\mathrm{U}^{\mathrm{III}}$, $\mathrm{U}^{\mathrm{IV}}$, and $\mathrm{U}^{\mathrm{V}}$ compounds, respectively. ${ }^{27,52}$ Unfortunately, chemical stability problems with 7a and 7b under the experimental conditions prevented accurate measurement of these compounds, thwarting our ultimate goal of oxidation-state deduction in multimetallic systems. All the data were collected simultaneously with a $\mathrm{UO}_{2}$ reference. The first derivative of the uranium $L_{\mathrm{III}}$-edge XANES for these reference spectra was set to $17166 \mathrm{eV}$ for one trace; the rest of the uranium $L_{\mathrm{III}}$-edge data were then calibrated and fit to this reference. This procedure generally yielded energy calibration accurate to $\sim 0.05$ 
$\mathrm{eV}$ between traces and an absolute error of $\sim 0.3 \mathrm{eV}$. Figure 7 shows the uranium $L_{\mathrm{III}}$-edge XANES for these complexes at room temperature.
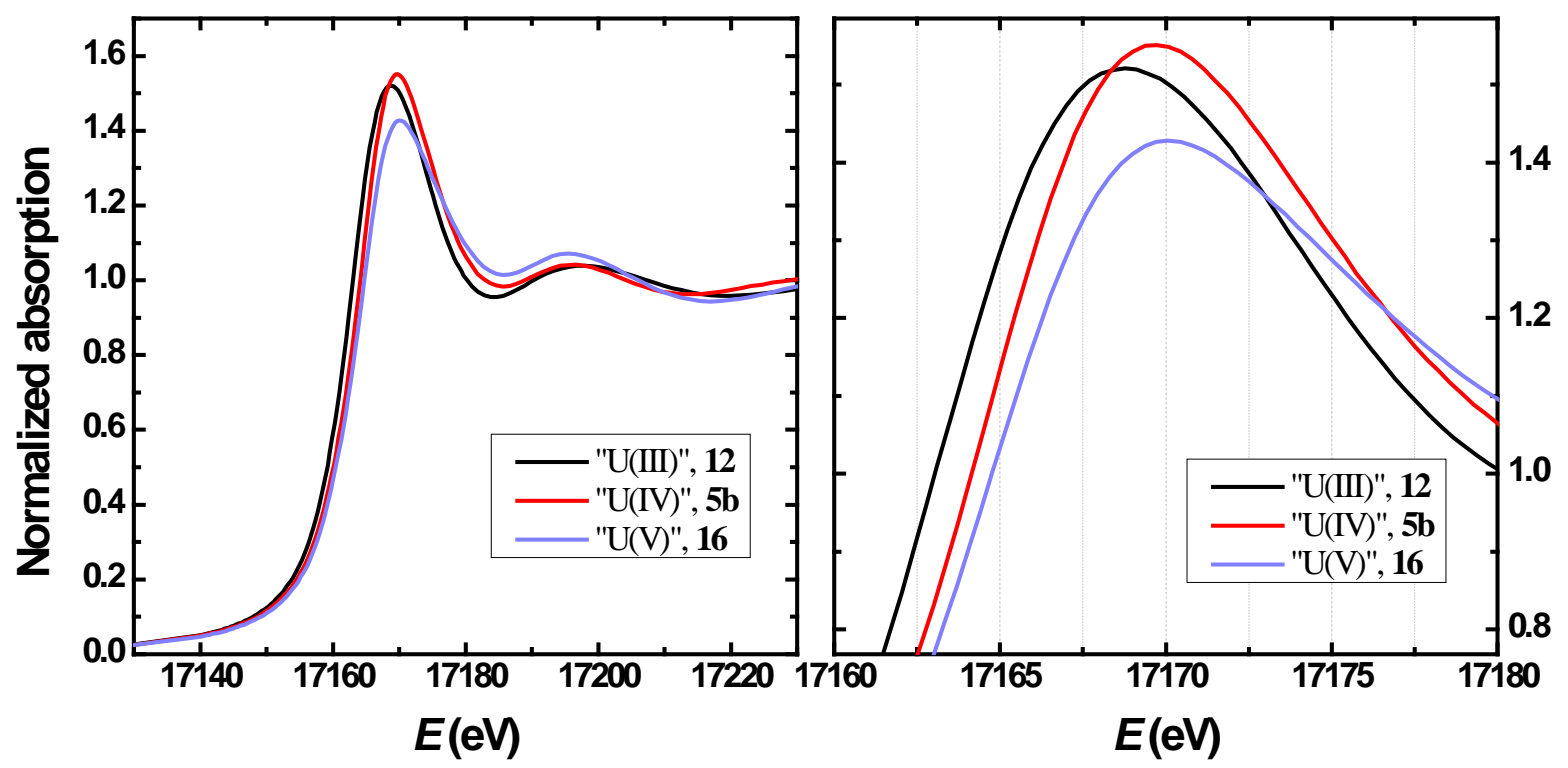

Figure 7. Normalized uranium $L_{\mathrm{III}}$-edge XANES data for $\mathbf{1 2}, \mathbf{5 b}$, and $\mathbf{1 6}$. The right panel is a magnification of the "white-line" peak near 17170 at left.

The main features of the data are the position of the main edge (half-height within $1 \mathrm{eV}$ of 17160 eV for all samples), the so-called "white-line" peak near $17170 \mathrm{eV}$, and the first EXAFS oscillation at $\sim 17195 \mathrm{eV}$. The "white-line" (WL) energy is due primarily to the $2 \mathrm{p}_{3 / 2}$ excitation into the lowest unoccupied uranium 6d-orbital, and is generally taken to be the best marker of the valence of the absorbing atom, ${ }^{53}$ although some component of the WL position is determined by the backscattering of the photoelectron off neighboring atoms. The WL peak height is a measure of the density of unoccupied states, and since the final photoelectron state is a $6 \mathrm{~d}$ state for all these spectra, the total area under that excitation should be constant; the spectral width of the final state accounts for differences in WL peak height.

Figure 7 indicates both the half-height and the WL positions are all within about $1 \mathrm{eV}$ for all samples 12, $5 \mathbf{b}$ and 16, consistent will the previous observation of Meyer for small differences in $L_{\text {III-edge WL }}$ energies for uranium organometallics. ${ }^{50}$ Figure 8 summarizes the WL positions for all the samples as a function of their nominal valence. 


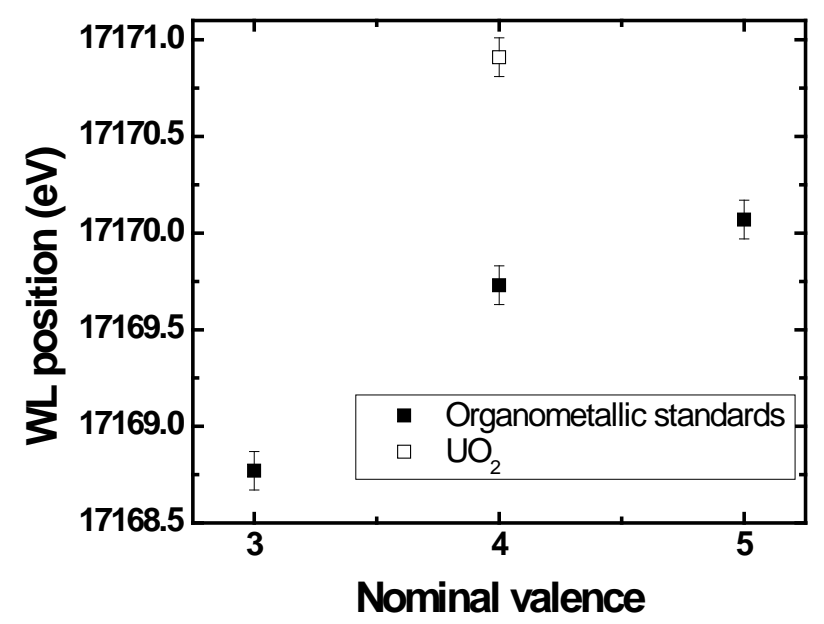

Figure 8. WL energy position, $E_{\mathrm{WL}}$, as a function of nominal valence. The open square represents $\mathrm{UO}_{2}$ and the solid squares represent the reference complexes $\mathbf{1 2}, \mathbf{5 b}$, and 16, as mentioned in the text. Reported errors indicate reproducibility. Systematic errors are estimated to be less than $0.3 \mathrm{eV}$.

Although the $\Delta E_{\mathrm{WL}}$ is small between the complexes, the $E_{\mathrm{WL}}$ generally increases with valence for $\mathbf{1 2}, \mathbf{5 b}$, and $\mathbf{1 6}$ as the Coulomb attraction between the ejected photoelectron and the net-positively-charged absorbing atoms increases. Relativistic calculations, absent of correlation effects, for metallic $L_{\mathrm{III}}$-edge chemical shifts with oxidation state are $\sim 4-6 \mathrm{eV} .{ }^{54}$ Similar $\Delta E_{\mathrm{WL}}$ values have been observed for trivalent and tetravalent compounds in inorganic actinide speciation studies, ${ }^{55}$ where the tetravalent $E_{\mathrm{WL}}$ is $\sim 4 \mathrm{eV}$ higher than the trivalent $E_{\mathrm{WL}}$. A smaller $\Delta E_{\mathrm{WL}}$ is reported for uranium halides and oxides, both with and without the uranyl geometry, on changing from tetravalent to pentavalent uranium. For example, $\Delta E_{\mathrm{WL}\left(\mathrm{UBr}_{3}-\mathrm{UBr}_{4}\right)}=4.1 \pm 0.3 \mathrm{eV}$ and $\Delta E_{\mathrm{WL}\left(\mathrm{UBr}_{4}-\mathrm{UBr}_{5}\right)}=1.6 \pm 0.3 \mathrm{eV} .{ }^{56,57}$ Although the overall energy differences on going from $\mathbf{1 2} \rightarrow \mathbf{5 b} \rightarrow \mathbf{1 6}$ are smaller than described for inorganic and metallic uranium species, the trend of $\Delta E_{\mathrm{WL}\left(\mathrm{U}^{\mathrm{III}}-\mathrm{U}^{\mathrm{IV}}\right)}>\Delta E_{\mathrm{WL}}\left(\mathrm{U}^{\mathrm{IV}}-\mathrm{U}^{\mathrm{V}}\right)$ is observed in the organometallic systems reported here. This discussion has assumed that the data can be interpreted at face value, using the estimated errors on the "white-line" to directly relate to errors in estimating the valence, in spite of the previously mentioned distribution of $E_{\mathrm{WL}}$ for given actinide valence species. ${ }^{53}$ Indeed, these results should not be taken as rigorous, as the differences in $E_{\mathrm{WL}}$ are quite small. 


\section{Conclusions}

We have presented a unique series of trimetallic actinide and mixed lanthanide-actinide and lanthanum-actinide complexes $\left(\mathrm{C}_{5} \mathrm{Me}_{5}\right)_{2} \mathrm{An}\left[-\mathrm{N}=\mathrm{C}(\mathrm{Bn})\left(\operatorname{tpy}-\mathrm{M}\left\{\mathrm{C}_{5} \mathrm{Me}_{4} \mathrm{R}\right\}_{2}\right)\right]_{2}\left(\right.$ where, $\mathrm{An}=\mathrm{Th}^{\mathrm{IV}}, \mathrm{U}^{\mathrm{IV}} ; \mathrm{M}$ $=\mathrm{La}^{\mathrm{III}}, \mathrm{Sm}^{\mathrm{III}}, \mathrm{Yb}^{\mathrm{III}}, \mathrm{U}^{\mathrm{III}} ; \mathrm{R}=\mathrm{H}, \mathrm{Me}, \mathrm{Et}$ ) which exhibit rich and diverse electronic structures that can be modulated through variation of the bridging $\mathrm{Th}^{\mathrm{IV}} / \mathrm{U}^{\mathrm{IV}}$ and peripheral " $\mathrm{M}^{\mathrm{III}}$ metal ions. Access to these compounds is accomplished using a general procedure by reaction of the monometallic ketimide systems $\left(\mathrm{C}_{5} \mathrm{Me}_{5}\right)_{2} \mathrm{Th}[-\mathrm{N}=\mathrm{C}(\mathrm{Bn})(\text { tpy })]_{2}(\mathbf{5 a})$ and $\left(\mathrm{C}_{5} \mathrm{Me}_{5}\right)_{2} \mathrm{U}\left[-\mathrm{N}=\mathrm{C}(\mathrm{Bn})(\text { tpy) }]_{2}(5 \mathbf{b})\right.$ with a divalent metal synthon, resulting in nominal reduction of the terpyridyl groups and coordination of metal ions in the terpyridyl wedge. Evidence for $5 \mathrm{f} / 6 \mathrm{~d}$-orbital covalency within the $\mathrm{M}-\mathrm{N}_{\text {tpy }}$ linkages is clearly seen on comparison of $4 \mathrm{f}$ and $5 \mathrm{f}$ complexes; shorter $\mathrm{U}-\mathrm{N}_{\text {tpy }}$ bond distances are observed contradictory to expectations based on ionic radii alone.

The ketimide organometallic framework used in this study is relatively stable in the conditions of the electrochemical experiments, such that electronic delocalization within the framework can be detected prior to decomposition of the complexes. The sum of the electrochemical data indicates electronic delocalization within the molecular framework. Most striking is the appearance of strong electronic coupling for the trimetallic $\mathrm{Yb}^{\mathrm{III}}-\mathrm{U}^{\mathrm{IV}}-\mathrm{Yb}^{\mathrm{III}}, \mathrm{Sm}^{\mathrm{III}}-\mathrm{U}^{\mathrm{IV}}-\mathrm{Sm}^{\mathrm{III}}$ and $\mathrm{La}^{\mathrm{III}}-\mathrm{U}^{\mathrm{IV}}-\mathrm{La}^{\mathrm{III}}$ complexes, [8]', [96- $]^{-}$and [10b]', respectively, whose calculated comproportionation constant $K_{c}$ is slightly larger than that reported for the benchmark Creutz-Taube ion. To the best of our knowledge, this information represents the first comprehensive study of f-element delocalization within an isostructural molecular framework. As electronic coupling between redox centers must involve their orbital overlap, it is clear from these data that these f-element complexes possess metal-ligand covalency and that electronic coupling can be used as a tool to evaluate the extent of orbital mixing in f-element complexes. Although sample degradation prevented analysis on multimetallic uranium complexes, $L_{\mathrm{III}}$-edge $\mathrm{X}$-ray absorption studies on related monomeric complexes provided complimentary data on the extent of orbital mixing in these complexes with the "white line" chemical shifts increasing with uranium oxidation state (UIII $\rightarrow \mathrm{U}^{\mathrm{IV}} \rightarrow$ $\mathrm{U}^{\mathrm{V}}$ ). 


\section{Experimental Section}

General Synthetic Procedures. Unless otherwise noted, reactions and manipulations were performed at ambient temperatures in either a recirculating Vacuum Atmospheres Model HE-553-2 inert atmosphere ( $\mathrm{N}_{2}$ or He) drybox with a MO-40-2 Dri-Train, a recirculating Vacuum Atmospheres NEXUS inert atmosphere $\left(\mathrm{N}_{2}\right)$ drybox equipped with a 40CFM Dual Purifier NI-Train, or using standard Schlenk techniques. Glassware was dried overnight at $150{ }^{\circ} \mathrm{C}$ before use. All NMR spectra were obtained using a Bruker Avance $300 \mathrm{MHz}$ spectrometer. Except when noted, NMR spectra were acquired at room temperature $\left(21^{\circ} \mathrm{C}\right)$. Chemical shifts were referenced to protio solvent impurities (toluene- $d_{8} \delta 2.08$ ppm; benzene- $d_{6} \delta 7.16 \mathrm{ppm}$ ), which are referenced to internal $\mathrm{SiMe}_{4}$ at $\delta 0.00 \mathrm{ppm}$. Elemental analyses were performed at the University of California, Berkeley Microanalytical facility on a Perkin Elmer Series II 2400 CHNS Analyzer.

Materials. Unless otherwise noted, reagents were purchased from commercial suppliers and used without further purification. Celite (Aldrich), alumina (Brockman I, Aldrich) and $4 \AA$ molecular sieves (Aldrich) were dried under dynamic vacuum at $250{ }^{\circ} \mathrm{C}$ for $48 \mathrm{~h}$ prior to use. Toluene (anhydrous, Aldrich), hexanes (anhydrous, Aldrich), pentane (anhydrous, Aldrich), tetrahydrofuran (anhydrous, Aldrich), and bis(trimethylsilyl)ether (Aldrich) were dried over KH for $24 \mathrm{~h}$, passed through a column of activated alumina under nitrogen and stored over activated $4 \AA \AA$ molecular sieves prior to use. Anhydrous toluene- $d_{8}$ and benzene- $d_{6}$ were obtained from Aldrich and were purified by storage over activated $4 \AA$

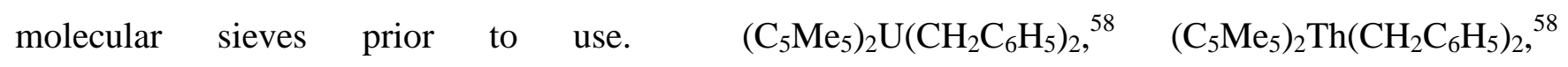
$\left[\mathrm{Bu}_{4} \mathrm{~N}\right]\left[\mathrm{B}\left(\mathrm{C}_{6} \mathrm{~F}_{5}\right)_{4}\right],,^{37,59-61} \quad\left[\mathrm{Bu}_{4} \mathrm{~N}\right]\left[\mathrm{B}\left\{3,5-\left(\mathrm{CF}_{3}\right)_{2}-\mathrm{C}_{6} \mathrm{H}_{3}\right\}_{4}\right],{ }^{62} \quad\left(\mathrm{C}_{5} \mathrm{Me}_{4} \mathrm{Et}\right)_{2} \mathrm{Sm}(\mathrm{THF})_{2},{ }^{63} \quad$ and $\left(\mathrm{C}_{5} \mathrm{Me}_{4} \mathrm{Et}\right)_{2} \mathrm{Yb}\left(\mathrm{OEt}_{2}\right),{ }^{64}$ were prepared according to literature procedures.

Caution: Depleted uranium (primarily isotope ${ }^{238} \mathrm{U}$ ) and natural thorium (isotope ${ }^{232} \mathrm{Th}$ ) are both weak $\alpha$-emitters with a half-life of $4.47 \times 10^{9}$ years and $1.41 \times 10^{10}$ years, respectively. Manipulations 
and reactions should be carried out in monitored fume hoods or in an inert atmosphere drybox in a radiation laboratory equipped with $\alpha$ - and $\beta$-counting equipment.

Synthesis of 4'-Cyano-2,2':6',2"-Terpyridine: This is a modification of the literature procedure. ${ }^{65}$ A one-necked round bottom flask was charged with 4'-chloro-2,2':6',2"-terpyridine (26.40 g, 98.61 mmol), potassium cyanide (8.35 g, $128.19 \mathrm{mmol})$, palladium acetate (0.53 g, $2.37 \mathrm{mmol})$, 1,5bis(diphenylphosphino)pentane (1.73 g, $3.92 \mathrm{mmol}), N, N, N^{\prime}, N^{\prime}$-tetramethylethylenediamine (5.92 mL, $39.22 \mathrm{mmol})$ and mesitylene (200 mL). The mixture was heated to reflux under argon for 3 days after which time TLC $\left(10 \% \mathrm{MeOH} / \mathrm{CH}_{2} \mathrm{Cl}_{2}\right.$, with $\left.1 \% \mathrm{NH}_{4} \mathrm{OH}\right)$ indicated that the reaction had gone to completion $\left(\mathrm{Rf}_{\text {tpy-Cl }}=0.57 ; \mathrm{Rf}_{\text {tpy-CN }}=0.80\right)$. Mass spectrometry can also be used to monitor the progress of the reaction. The reaction was cooled to room temperature, water (100 mL) was added, and the mixture was stirred until the solid chunks became a fine suspension. The solids were filtered through filter paper and the organic layer was collected from the filtrate. The solvent from the organic layer was removed under reduced pressure $\left(50{ }^{\circ} \mathrm{C} / 15 \mathrm{mmHg}\right)$ to give a solid residue. This solid and the solids collected by filtration were combined and dissolved in dichloromethane ( 50 mL) and silica gel ( 10g) was added. The solvent was removed by rotary evaporation and the residue was loaded on a silica gel column $(7 \mathrm{~cm} \times 15 \mathrm{~cm})$. The product was eluted with $10 \% \mathrm{MeOH} / \mathrm{CH}_{2} \mathrm{Cl}_{2}$ (approx. 1L). The solvent was then removed by rotary evaporation and the residue was dried under reduced pressure (0.1-0.5 mmHg) overnight to give 4'-cyano-2,2':6',2"-terpyridine as a white solid (24.85 g, 98\%). LC-MS-ESI: m/z (M+1) 259.2 (calcd 259.1). Spectroscopic characterization matches literature data: ${ }^{65}{ }^{1} \mathrm{H}$ NMR $\left(\mathrm{CDCl}_{3}\right): \delta 8.71(\mathrm{dd}, \mathrm{J}=4.82,0.82 \mathrm{~Hz}, 2 \mathrm{H}), 8.70(\mathrm{~s}, 2 \mathrm{H}), 8.59(\mathrm{dd}, \mathrm{J}=7.95,0.82 \mathrm{~Hz}, 2 \mathrm{H}), 7.88(\mathrm{dt}, \mathrm{J}=$ 7.95, $1.75 \mathrm{~Hz}, 2 \mathrm{H}), 7.39$ (ddd, J = 7.51, 4.77, $1.04 \mathrm{~Hz}, 2 \mathrm{H}) .{ }^{13} \mathrm{C} \mathrm{NMR}\left(\mathrm{CDCl}_{3}\right): \delta 156.9,154.5,149.7$, $137.4,125.0,122.7,122.6,121.5,117.2$.

Synthesis of $\left(\mathbf{C}_{5} \mathbf{M e}_{5}\right)_{2} \mathbf{T h}[-\mathbf{N}=\mathbf{C}(\mathbf{B n})(\mathbf{t p y})]_{2}$ (5a): A $125 \mathrm{~mL}$ side-arm flask equipped with a stir bar was charged with $\left(\mathrm{C}_{5} \mathrm{Me}_{5}\right)_{2} \mathrm{Th}\left(\mathrm{CH}_{2} \mathrm{C}_{6} \mathrm{H}_{5}\right)_{2}(0.51 \mathrm{~g}, 0.74 \mathrm{mmol})$ and toluene $(30 \mathrm{~mL})$. To this pale yellow solution was slowly added 4'-cyano-2,2':6',2"-terpyridine (0.39 g, $1.49 \mathrm{mmol})$. The resulting reaction mixture immediately turned a dark green color and was stirred at ambient temperature for $3 \mathrm{~h}$ and 
filtered through a Celite-padded coarse-porosity fritted filter. The filtrate was collected, the volume reduced $(\sim 5-10 \mathrm{~mL})$, layered with $\sim 60 \mathrm{~mL}$ pentane, and placed in a $-30^{\circ} \mathrm{C}$ freezer to afford $5 \mathbf{a}$ as a dark green crystalline solid (0.34 g, $0.28 \mathrm{mmol}, 38 \%)$. Analytically pure samples of 5a were obtained by recrystallization from toluene/pentane at $-30{ }^{\circ} \mathrm{C} .{ }^{1} \mathrm{H}$ NMR (benzene- $d_{6}, 25^{\circ} \mathrm{C}$ ): $\delta 9.22$ (s, 4H, tpy-Ar-H), 8.61 (m, 8H, Ar-H), 7.40 (d, J = 7.2 Hz, 4H, Ar-H), 7.29 (td, J = 7.5, 1.5 Hz, 4H, Ar-H), 7.04 (t, J = 7.5 Hz, 4H, Ar-H), 6.90 (t, J = 7.5 Hz, 4H, Ar-H), 6.77 (m, 4H, Ar-H), 4.21 (s, 4H, -CH $\left.\mathrm{CH}_{2} \mathrm{Ph}\right), 2.18$ (s, 30H, $\left.\mathrm{C}_{5} \mathrm{Me}_{5}\right)$. Anal. Calc'd for $\mathbf{5 a}\left(\mathrm{C}_{66} \mathrm{H}_{63} \mathrm{~N}_{8} \mathrm{Th}, 1200.3 \mathrm{~g} / \mathrm{mol}\right)$ : C, 65.99; H, 5.37; N, 9.33. Found: C, 65.89; H, 5.40; N, 8.98. Note: The order of addition of reagents is important for this reaction. Addition of $\left(\mathrm{C}_{5} \mathrm{Me}_{5}\right)_{2} \mathrm{Th}\left(\mathrm{CH}_{2} \mathrm{C}_{6} \mathrm{H}_{5}\right)_{2}$ to solutions of 4'-cyano-2,2':6',2"-terpyridine produced mixtures of as yet undetermined products.

Synthesis of $\left(\mathbf{C}_{5} \mathbf{M e}_{5}\right)_{2} \mathbf{U}[-\mathbf{N}=\mathbf{C}(\mathbf{B n})(t p y)]_{2}$ (5b): A $125 \mathrm{~mL}$ side-arm flask equipped with a stir bar was charged with $\left(\mathrm{C}_{5} \mathrm{Me}_{5}\right)_{2} \mathrm{U}\left(\mathrm{CH}_{2} \mathrm{C}_{6} \mathrm{H}_{5}\right)_{2}(0.52 \mathrm{~g}, 0.75 \mathrm{mmol})$ and toluene $(30 \mathrm{~mL})$. To this dark, brown solution was slowly added 4'-cyano-2,2':6',2"-terpyridine (0.40 g, $1.53 \mathrm{mmol})$. The resulting reaction mixture immediately turned a dark green color and was stirred at ambient temperature for $14 \mathrm{~h}$ and then filtered hot through a Celite-padded coarse-porosity fritted filter. The green filtrate was collected, the volume reduced ( $\sim 5-10 \mathrm{~mL})$, layered with $75 \mathrm{~mL}$ hexane, and placed in a $-30^{\circ} \mathrm{C}$ freezer to afford $5 \mathbf{b}$ as a dark green solid crystalline solid, which was washed with hexanes $(3 \times 10 \mathrm{~mL})$ and dried under reduced pressure $(0.56 \mathrm{~g}, 0.46 \mathrm{mmol}, 61 \%)$. Analytically pure samples of $\mathbf{5 b}$ were obtained by recrystallization toluene/pentane at $-30{ }^{\circ} \mathrm{C} .{ }^{1} \mathrm{H}$ NMR (toluene- $d_{8}, 65{ }^{\circ} \mathrm{C}$ ): $\delta 10.79$ (br s, $4 \mathrm{H}$, tpy-Ar-H), 10.01 (br s, $4 \mathrm{H}$, tpy-Ar-H), 8.75 (br s, 4H, tpy-Ar-H), 7.64 (br s, 4H, tpy-Ar-H), 7.36 (br s, 2H, p- $\mathrm{CH}_{2} \mathrm{C}_{6} \mathrm{H}_{5}$ ), 6.60 (br s, 4H, o/m- $\mathrm{CH}_{2} \mathrm{C}_{6} \mathrm{H}_{5}$ ), 6.44 (br s, $4 \mathrm{H}, o / m-\mathrm{CH}_{2} \mathrm{C}_{6} \mathrm{H}_{5}$ ), 6.14 (br s, 4H, tpy-Ar-H), 3.54 (s, 4H, $-\mathrm{CH}_{2} \mathrm{Ph}$ ), 0.87 (s, 30H, $\left.\mathrm{C}_{5} M e_{5}\right)$. Anal. Calc'd for $5 \mathbf{b} \cdot 1 / 2 \mathrm{C}_{7} \mathrm{H}_{8}\left(\mathrm{C}_{69.5} \mathrm{H}_{67} \mathrm{~N}_{8} \mathrm{U}, 1252.4 \mathrm{~g} / \mathrm{mol}\right): \mathrm{C}, 66.60 ; \mathrm{H}, 5.47 ; \mathrm{N}$, 8.94. Found: C, 66.63; H, 5.28; N, 8.56. Note: The order of addition of reagents is important for this reaction. Addition of $\left(\mathrm{C}_{5} \mathrm{Me}_{5}\right)_{2} \mathrm{U}\left(\mathrm{CH}_{2} \mathrm{C}_{6} \mathrm{H}_{5}\right)_{2}$ to solutions of 4'-cyano-2,2':6',2"-terpyridine produced mixtures of as yet undetermined products. 
Synthesis of $\left(\mathrm{C}_{5} \mathbf{M e}_{5}\right)_{2} \mathrm{U}\left[-\mathbf{N}=\mathbf{C}(\mathrm{Bn})\left(\mathbf{t p y}-\mathbf{Y b}\left\{\mathrm{C}_{5} \mathbf{M e}_{4} \mathbf{E t}\right\}_{2}\right)\right]_{2}$ (8): A 125-mL side-arm flask equipped with a stir bar was charged with $\left(\mathrm{C}_{5} \mathrm{Me}_{5}\right)_{2} \mathrm{U}[-\mathrm{N}=\mathrm{C}(\mathrm{Bn})(\mathrm{tpy})]_{2}(5 \mathbf{b})(0.47 \mathrm{~g}, 0.39 \mathrm{mmol})$ and toluene (50 mL). To this dark green solution, $\left(\mathrm{C}_{5} \mathrm{Me}_{4} \mathrm{Et}\right)_{2} \mathrm{Yb}\left(\mathrm{OEt}_{2}\right)(0.43 \mathrm{~g}, 0.78 \mathrm{mmol}, 2.0$ equiv. $)$ was added and the mixture was stirred at ambient temperature for $14 \mathrm{~h}$. The mixture was then filtered through a Celitepadded coarse-porosity fritted filter, the filtrate collected and reduced to $5 \mathrm{~mL}$, and $50 \mathrm{~mL}$ pentane was added with stirring. Dark green, crystalline $\mathbf{8}$ deposited from solution and collected by decanting the supernatant, washing with pentane $(3 \times 10 \mathrm{~mL})$ and drying under reduced pressure $(0.53 \mathrm{~g}, 0.25 \mathrm{mmol}$, $63 \%$ ). ${ }^{1} \mathrm{H}$ NMR (toluene- $\left.d_{8}, 25{ }^{\circ} \mathrm{C}\right): \delta 27.58$ (br s, 2H, tpy-Ar-H), 25.78 (br s, 2H, tpy-Ar-H), 19.92 (br s, 2H, tpy-Ar-H), 15.98 (br s, 2H, tpy-Ar-H), 10.89 (br s, 4H, $\mathrm{CH}_{2}-m-\mathrm{Ar}-H$ ), 9.91 (br s, 2H, $\mathrm{CH}_{2}-p-\mathrm{Ar}-$ $H$ ), 8.68 (br s, 4H, $\mathrm{CH}_{2}-\mathrm{O}-\mathrm{Ar}-H$ ), 8.06 (br s, 2H, tpy-Ar-H), 5.55 (br s, 2H, tpy-Ar-H), 5.07 (br s, 2H, tpy-Ar-H), 0.06 (br s, $12 \mathrm{H}, \mathrm{C}_{5} \mathrm{Me}_{4} \mathrm{Et}$ ), -0.65 (br s, 2H, tpy-Ar-H, overlapping with -0.90), -0.90 (s, $30 \mathrm{H}$, $\mathrm{C}_{5} \mathrm{Me}_{5}$ ), -1.45 (br s, 6H, $\mathrm{C}_{5} \mathrm{Me}_{4}\left(\mathrm{CH}_{2} \mathrm{CH}_{3}\right)$ ), -2.50 (br s, $12 \mathrm{H}, \mathrm{C}_{5} \mathrm{Me}_{4} \mathrm{Et}$ ), -3.16 (br s, 12H, $\mathrm{C}_{5} \mathrm{Me}_{4} \mathrm{Et}$ ), 3.86 (br s, $4 \mathrm{H}, \mathrm{C}_{5} \mathrm{Me}_{4}\left(\mathrm{CH}_{2} \mathrm{CH}_{3}\right)$ ), -5.72 (br s, $12 \mathrm{H}, \mathrm{C}_{5} \mathrm{Me}_{4} \mathrm{Et}$ ), -9.77 (br s, $6 \mathrm{H}, \mathrm{C}_{5} \mathrm{Me}_{4}\left(\mathrm{CH}_{2} \mathrm{CH}_{3}\right)$ ), -11.17 (br s, 2H, tpy-Ar-H), -11.42 (br s, 4H, $\mathrm{C}_{5} \mathrm{Me}_{4}\left(\mathrm{CH}_{2} \mathrm{CH}_{3}\right)$ ). Anal. Calcd for $\mathbf{8} \cdot 2\left(\mathrm{C}_{7} \mathrm{H}_{8}\right)$ $\left(\mathrm{C}_{138} \mathrm{H}_{162} \mathrm{~N}_{8} \mathrm{UYb}_{2} \cdot 2\left(\mathrm{C}_{7} \mathrm{H}_{8}\right), 2516.9 \mathrm{~g} / \mathrm{mol}\right): \mathrm{C}, 63.79 ; \mathrm{H}, 6.39 ; \mathrm{N}, 4.80$. Found: C, 63.87; H, 6.89; N, 4.61.

Synthesis of $\left(\mathrm{C}_{5} \mathbf{M e}_{5}\right)_{2} \mathbf{T h}\left[-\mathbf{N}=\mathbf{C}(\mathrm{Bn})\left(\mathbf{t p y}-\mathrm{Sm}\left\{\mathrm{C}_{5} \mathbf{M e}_{4} \mathrm{Et}\right\}_{2}\right)\right]_{2} \quad$ (9a): A 125-mL side-arm flask equipped with a stir bar was charged with $\left(\mathrm{C}_{5} \mathrm{Me}_{4} \mathrm{Et}\right)_{2} \mathrm{Sm}(\mathrm{THF})(0.41 \mathrm{~g}, 0.69 \mathrm{mmol})$ and toluene (50 $\mathrm{mL})$. To this maroon colored solution, green $\left(\mathrm{C}_{5} \mathrm{Me}_{5}\right)_{2} \mathrm{Th}[-\mathrm{N}=\mathrm{C}(\mathrm{Bn})(\mathrm{tpy})]_{2}(5 \mathrm{a})(0.41 \mathrm{~g}, 0.34 \mathrm{mmol})$ was added with stirring, resulting in a dark green mixture. The mixture was stirred at ambient temperature for $48 \mathrm{~h}$ and filtered through a Celite-padded coarse-porosity fritted filter. The filtrate was collected and the volatiles removed. The resulting residue was triturated with $10 \mathrm{~mL}$ pentane and dried under reduced pressure to give 9a as a dark green solid (0.58 g, $0.28 \mathrm{mmol}, 80 \%) .{ }^{1} \mathrm{H}$ NMR (benzene- $\left.d_{6}, 29{ }^{\circ} \mathrm{C}\right): \delta$ 7.07 (m, 4H, CH $2-m-A r-H), 6.55$ (d, J = 6 Hz, 4H, CH $2-O-A r-H), 6.10$ (t, J = 6 Hz, 2H, CH $2-p-A r-H)$, 4.73 (s, 30H, C $M_{5}$ ), 2.90 (br s, 24H, C ${ }_{5} \mathrm{Me}_{4} \mathrm{Et}$ ), 2.63 (br s, 24H, C ${ }_{5} M e_{4} \mathrm{Et}$ ), 2.32 (q, J = $6 \mathrm{~Hz}, 8 \mathrm{H}$, $\left.\mathrm{C}_{5} \mathrm{Me}_{4}\left(\mathrm{CH}_{2} \mathrm{CH}_{3}\right)\right), 2.32$ (q, J = $6 \mathrm{~Hz}, 8 \mathrm{H}, \mathrm{C}_{5} \mathrm{Me}_{4}\left(\mathrm{CH}_{2} \mathrm{CH}_{3}\right)$ ), 2.16 (br s, 4H, - $\left.\mathrm{CH}_{2}-\mathrm{Ar}\right), 1.73$ (t, J = $6 \mathrm{~Hz}$, 
$\left.12 \mathrm{H}, \mathrm{C}_{5} \mathrm{Me}_{4}\left(\mathrm{CH}_{2} \mathrm{CH}_{3}\right)\right)$. Additional ${ }^{1} \mathrm{H}$ resonances were not observed due to paramagnetic relaxation. Anal. Calcd for 9a $\left(\mathrm{C}_{110} \mathrm{H}_{130} \mathrm{~N}_{8} \mathrm{Sm}_{2} \mathrm{Th}, 2097.1 \mathrm{~g} / \mathrm{mol}\right)$ : C, 62.94; H, 6.34; N, 5.34. Found: C, 62.35; H, 6.44; N, 5.10 .

Synthesis of $\left(\mathrm{C}_{5} \mathbf{M e}_{5}\right)_{2} \mathrm{U}\left[-\mathrm{N}=\mathrm{C}(\mathrm{Bn})\left(\mathrm{tpy}-\mathrm{Sm}\left\{\mathrm{C}_{5} \mathbf{M e}_{4} \mathrm{Et}\right\}_{2}\right)\right]_{2}(\mathbf{9 b})$ : A 125-mL side-arm flask equipped with a stir bar was charged with $\left(\mathrm{C}_{5} \mathrm{Me}_{4} \mathrm{Et}\right)_{2} \mathrm{Sm}(\mathrm{THF})(0.21 \mathrm{~g}, 0.36 \mathrm{mmol}, 2.0$ equiv.) and toluene (50 $\mathrm{mL})$. To this maroon colored solution, green $\left(\mathrm{C}_{5} \mathrm{Me}_{5}\right)_{2} \mathrm{U}[-\mathrm{N}=\mathrm{C}(\mathrm{Bn})(\mathrm{tpy})]_{2}(5 \mathbf{b})(0.21 \mathrm{~g}, 0.18 \mathrm{mmol})$ was added with stirring, resulting in a dark green mixture. The mixture was stirred at ambient temperature for $14 \mathrm{~h}$ then filtered through a Celite-padded coarse-porosity fritted filter. The dark green filtrate was collected; the volume reduced to $5 \mathrm{~mL}$, and then $40 \mathrm{~mL}$ pentane was added. This pentane/toluene solution was chilled to $-35{ }^{\circ} \mathrm{C}$ to deposit a dark-green solid, which was collected by vacuum filtration using a medium porosity frit. The dark green solid was washed pentane $(3 \times 10 \mathrm{~mL})$ and dried under reduced pressure. Analytically pure $\mathbf{9 b}$ was obtained by recrystallization from diethyl ether (0.09 $\mathbf{g}$, 0.044 mmol, 25\%). ${ }^{1} \mathrm{H}$ NMR (toluene- $d_{8},-25{ }^{\circ} \mathrm{C}$ ): $\delta 13.93$ (br s, $1 \mathrm{H}$, tpy-Ar-H), 12.05 (br d, J = $15 \mathrm{~Hz}$, 1H, tpy-Ar-H), 9.06 (br s, 1H, tpy-Ar-H), 8.03 (br d, J = 7.2 Hz, 4H, o-Ar- $H$ ), 6.89 (br t, J = 7.2 Hz, 4H, m-Ar-H), 6.65 (br t, J = 7.2 Hz, 4H, p-Ar-H), 4.63 (br s, 1H, tpy-Ar-H), 4.08 (br d, J = 7.2 Hz, $1 \mathrm{H}$, tpyAr- $H$ ), 3.70 (br s, 30H, C $\mathrm{Me}_{5}$ ), 2.75 (br s, $1 \mathrm{H}$, tpy-Ar-H), 1.97 (br s, $12 \mathrm{H}, \mathrm{C}_{5} M e_{4} \mathrm{Et}$ ), 1.93 (br s, 4H, $\mathrm{C}_{5} \mathrm{Me}_{4}\left(\mathrm{CH}_{2} \mathrm{CH}_{3}\right)$ ), 1.82 (br s, 6H, ${ }_{5} \mathrm{Me}_{4}\left(\mathrm{CH}_{2} \mathrm{CH}_{3}\right)$ ), 1.67 (br s, $12 \mathrm{H}, \mathrm{C}_{5} \mathrm{Me}_{4} \mathrm{Et}$ ), 1.66 (br s, $12 \mathrm{H}$, $\mathrm{C}_{5} \mathrm{Me}_{4} \mathrm{Et}$ ), 1.58 (br s, 12H, $\mathrm{C}_{5} \mathrm{Me}_{4} \mathrm{Et}$ ), 1.53 (br s, 4H, $\left.\mathrm{C}_{5} \mathrm{Me}_{4}\left(\mathrm{CH}_{2} \mathrm{CH}_{3}\right)\right), 1.34$ (br s, 6H, $\mathrm{C}_{5} \mathrm{Me}_{4}\left(\mathrm{CH}_{2} \mathrm{CH}_{3}\right.$ )), 0.67 (br s, $1 \mathrm{H}$, tpy-Ar- $H$ ), 0.34 (br s, $1 \mathrm{H}$, tpy-Ar- $H$ ), 0.07 (br s, $1 \mathrm{H}$, tpy-Ar- $H$ ), -0.29 (br s, 1H, tpy-Ar-H), -0.70 (br s, $1 \mathrm{H}$, tpy-Ar-H), -1.47 (br s, 1H, tpy-Ar- $H$ ), -2.00 (br d, J = 29 Hz, 1H, tpy-Ar-H), -2.31 (br s, $1 \mathrm{H}$, tpy-Ar- $H$ ), -3.05 (br d, J = $16 \mathrm{~Hz}, 1 \mathrm{H}$, tpy-Ar-H), -3.87 (br s, $1 \mathrm{H}$, tpy-Ar- $H$ ), -4.63 (br s, $1 \mathrm{H}$, tpy-Ar-H), -12.45 (br s, $1 \mathrm{H}$, tpy-Ar-H), -13.91 (br s, $1 \mathrm{H}$, tpy-Ar- $H$ ). Additional ${ }^{1} \mathrm{H}$ resonances were not observed due to paramagnetic relaxation. Anal. Calcd for $\mathbf{9 b} 4\left(\mathrm{Et}_{2} \mathrm{O}\right)$ $\left(\mathrm{C}_{110} \mathrm{H}_{130} \mathrm{~N}_{8} \mathrm{Sm}_{2} \mathrm{U}, 2399.6\right.$ g/mol): C, 63.07; H, 7.14; N, 4.67. Found: C, 63.48; H, 6.83; N, 4.88.

Synthesis of $\left(\mathrm{C}_{5} \mathrm{Me}_{5}\right)_{2} \mathrm{Th}\left[-\mathrm{N}=\mathrm{C}(\mathrm{Bn})\left(\mathrm{tpy}-\mathrm{La}\left\{\mathrm{C}_{5} \mathrm{Me}_{4} \mathrm{H}\right\}_{2}\right)\right]_{2}$ (10a): Potassium graphite $\left(\mathrm{KC}_{8}\right)$ was prepared for immediate use by heating potassium metal $(0.033 \mathrm{~g}, 0.84 \mathrm{mmol}, 3.2$ equiv.) with graphite 
(0.064 g, $5.33 \mathrm{mmol}, 6.3$ equiv.) in a $20 \mathrm{~mL}$ scintillation vial at $150{ }^{\circ} \mathrm{C}$ for $15 \mathrm{~min}$. Addition of $10 \mathrm{~mL}$ THF yielded a copper-colored suspension, to which yellow $\left(\mathrm{C}_{5} \mathrm{Me}_{4} \mathrm{H}\right)_{3} \mathrm{La}(0.266 \mathrm{~g}, 0.529 \mathrm{mmol}, 2.0$ equiv.) was added with stirring. On addition, the yellow color of $\left(\mathrm{C}_{5} \mathrm{Me}_{4} \mathrm{H}\right)_{3} \mathrm{La}$ immediately vanished to produce a dark yellow suspension with formation of a white precipitate. The mixture was stirred at ambient temperature for $1.5 \mathrm{~h}$ and dark green $\left(\mathrm{C}_{5} \mathrm{Me}_{5}\right)_{2} \mathrm{Th}[-\mathrm{N}=\mathrm{C}(\mathrm{Bn})(\mathrm{tpy})]_{2}(5 \mathbf{a})(0.368 \mathrm{~g}, 0.26 \mathrm{mmol})$ was added, resulting in gas evolution and formation of a dark green reaction mixture. The dark green mixture was stirred for $16 \mathrm{~h}$ at room temperature. This mixture was then filtered through a Celitepadded coarse-porosity fritted filter, the dark green filtrate collected, and the volatiles removed under reduced pressure to afford a dark green solid. The solid was dissolved in $10 \mathrm{~mL}$ THF and $20 \mathrm{~mL}$ $\mathrm{TMS}_{2} \mathrm{O}$ was added. Evaporation of the solution at ambient temperature over 5 days produced 10a as a dark green microcrystalline solid (0.44 g, $0.23 \mathrm{mmol}, 86 \%$ ). ${ }^{1} \mathrm{H}$ NMR (toluene- $d_{8}, 80{ }^{\circ} \mathrm{C}$ ): $\delta 10.30$ (br s, 4H, tpy-Ar-H), 7.22 (br s, 4H, $\mathrm{CH}_{2}-\mathrm{O}-\mathrm{Ar}-H$ ), 6.55 (br s, 8H, $\mathrm{CH}_{2}-\mathrm{m} / \mathrm{p}-\mathrm{Ar}-\mathrm{H}$ ), 4.92 (br s, 4H, tpy-Ar-H), 4.32 (br s, 4H, CH2-Ar), 3.98 (br s, 24H, C ${ }_{5} \mathrm{Me}_{4} \mathrm{H}$ ), 3.39 (br s, 4H, $\mathrm{C}_{5} \mathrm{Me}_{4} H$ ), 3.15 (br s, 24H, $\mathrm{C}_{5} M e_{4} \mathrm{H}$ ), 1.89 (br s, 30H, $\mathrm{C}_{5} \mathrm{Me}_{5}$ ), -1.95 (br s, 4H, tpy-Ar-H). Additional ${ }^{1} \mathrm{H}$ resonances were not observed due to paramagnetic broadening. Anal. Calcd for 10a· $\mathrm{TMS}_{2} \mathrm{O}\left(\mathrm{C}_{108} \mathrm{H}_{132} \mathrm{Si}_{2} \mathrm{ON}_{8} \mathrm{La}_{2} \mathrm{Th}, 2124.3 \mathrm{~g} / \mathrm{mol}\right)$ : C, 61.00; H, 6.35; N, 5.27. Found: C, 61.03; H, 5.87; N, 5.32.

Synthesis of $\left(\mathrm{C}_{5} \mathrm{Me}_{5}\right)_{2} \mathrm{U}\left[-\mathrm{N}=\mathrm{C}(\mathrm{Bn})\left(\mathrm{tpy}-\mathrm{La}\left\{\mathrm{C}_{5} \mathrm{Me}_{4} \mathbf{H}\right\}_{2}\right)\right]_{2}(\mathbf{1 0 b})$ : Potassium graphite $\left(\mathrm{KC}_{8}\right)$ was prepared and used immediately by heating potassium metal (0.045 g, $1.15 \mathrm{mmol}, 2.1$ equiv.) with graphite (0.151 g, $12.5 \mathrm{mmol}, 11$ equiv.) in a $20 \mathrm{~mL}$ scintillation vial at $150{ }^{\circ} \mathrm{C}$ for $15 \mathrm{~min}$. Addition of $5 \mathrm{~mL}$ THF yielded a copper-colored suspension, to which yellow $\left(\mathrm{C}_{5} \mathrm{Me}_{4} \mathrm{H}\right)_{3} \mathrm{La}(0.558 \mathrm{~g}, 1.11 \mathrm{mmol}$, 2.02 equiv.) and a stir bar was added. White precipitate formed immediately and the suspension turned dark yellow while stirring at ambient temperature for $4 \mathrm{~h}$. Next, the suspension was added to a $125-\mathrm{mL}$ side-arm flask and the THF removed under reduced pressure giving a yellowish, tacky solid. The residue was then dissolved in $30 \mathrm{~mL}$ toluene and dark green $\left(\mathrm{C}_{5} \mathrm{Me}_{5}\right)_{2} \mathrm{U}[-\mathrm{N}=\mathrm{C}(\mathrm{Bn})(\mathrm{tpy})]_{2}$ (5b) $(0.664 \mathrm{~g}$, $0.55 \mathrm{mmol}$ ) was added with stirring. The dark suspension was stirred at ambient temperature for $14 \mathrm{~h}$, filtered through a Celite-padded coarse-porosity fritted filter, the filtrate collected and the volatiles 
removed to yield a dark blue residue. The residue was then extracted $3 \times 10 \mathrm{~mL}$ with a $1: 1(\mathrm{v} / \mathrm{v})$ mixture of THF:TMS $2 \mathrm{O}$ and the combined blue solutions filtered through a Celite-padded coarseporosity fritted filter. Evaporation of the solution at ambient temperature over 5 days produced $\mathbf{1 0 b}$ as a blue microcrystalline solid (0.275 g, $0.140 \mathrm{mmol}, 25 \%)$. X-ray quality crystals of 10b were obtained by chilling a concentrated solution of diethyl ether to $-35{ }^{\circ} \mathrm{C} .{ }^{1} \mathrm{H}$ NMR (benzene- $d_{6}, 27{ }^{\circ} \mathrm{C}$ ): $\delta 15.16$ (br s, 1H, tpy-Ar-H), 12.77 (br d, J = 12 Hz, 1H, tpy-Ar-H), 8.82 (br s, 1H, tpy-Ar-H), 8.46 (br d, J = 7.2 Hz, 4H, o-Ar-H), 7.50 (br s, 1H, tpy-Ar-H), 7.28 (t, J = 7.2 Hz, 2H, p-Ar-H), 7.03 (t, J = 7.2 Hz, 4H, m-ArH), 6.65 (br s, 1H, tpy-Ar-H), 5.66 (br s, 1H, tpy-Ar-H), 4.93 (br d, J = 6.6 Hz, 1H, tpy-Ar-H), 4.75 (br s, $1 \mathrm{H}$, tpy-Ar- $H$ ), 3.51 (s, 30H, C $\mathrm{Me}_{5}$ ), 2.49 (br s, $1 \mathrm{H}$, tpy-Ar- $H$ ), 2.28 (br s, $12 \mathrm{H}, \mathrm{C}_{5} M e_{4} \mathrm{H}$ ), 2.18 (br s, 2H, $\mathrm{C}_{5} \mathrm{Me}_{4} H$ ), 1.41 (br s, 2H, $\mathrm{C}_{5} \mathrm{Me}_{4} H$ ), 1.25 (br s, $12 \mathrm{H}, \mathrm{C}_{5} \mathrm{Me}_{4} \mathrm{H}$ ), 0.79 (br s, 4H, $\mathrm{CH}_{2}-\mathrm{Ar}$ ), -2.19 (br s, 1H, tpy-Ar-H), -2.64 (br d, J = 15 Hz, $1 \mathrm{H}$, tpy-Ar-H), -2.96 (br s, $1 \mathrm{H}$, tpy-Ar-H), -3.48 (br s, $1 \mathrm{H}$, tpy-Ar$H$ ), -3.91 (br s, $1 \mathrm{H}$, tpy-Ar-H), -13.72 (br s, 1H, tpy-Ar-H). Additional proton resonances were not observed due to paramagnetic relaxation. Anal. Calcd for $\mathbf{1 0 b} \cdot \mathrm{TMS}_{2} \mathrm{O}\left(\mathrm{C}_{108} \mathrm{H}_{132} \mathrm{Si}_{2} \mathrm{ON}_{8} \mathrm{La}_{2} \mathrm{U}, 2130.3\right.$ g/mol): C, 62.25; H, 5.84; N, 5.69. Found: C, 62.30; H, 5.80; N, 5.84.

Electrochemistry. Cyclic voltammetric data were obtained at room temperature in the Vacuum Atmosphere drybox systems described above. All data were collected using a Perkin Elmer Princeton Applied Research Corporation (PARC) Model 263 potentiostat under computer control with PARC Model 270 software. All sample solutions were $\sim 1-10 \mathrm{mM}$ in complex with $0.1 \mathrm{M}\left[\mathrm{Bu}_{4} \mathrm{~N}\right]\left[\mathrm{B}\left(\mathrm{C}_{6} \mathrm{~F}_{5}\right)_{4}\right]$ or $\left[\mathrm{Bu}_{4} \mathrm{~N}\right]\left[\mathrm{B}\left\{3,5-\left(\mathrm{CF}_{3}\right)_{2}-\mathrm{C}_{6} \mathrm{H}_{3}\right\}_{4}\right]$ supporting electrolytes in THF solvent. All data were collected with the positive-feedback IR compensation feature of the software/potentiostat activated to ensure minimal contribution to the voltammetric waves from uncompensated solution resistance (typically $\sim 1 \mathrm{k} \Omega$ under the conditions employed). Solutions were contained in PARC Model K0264 microcells consisting of a 3 mm diameter Pt working electrode, a Pt wire counter electrode, and a Ag wire quasi-reference electrode. Scan rates from $20-5000 \mathrm{mV} / \mathrm{s}$ were employed to assess the chemical and electrochemical reversibility of the observed redox transformations. Potential calibrations were performed at the end of each data collection cycle using the ferrocene/ferrocenium $\left(\mathrm{Fc} / \mathrm{Fc}^{+}\right)$couple as an internal standard. 
Voltammetric data were analyzed using Wavemetrics IGOR Pro® (Version 4.0) software on a Macintosh platform.

X-Ray Crystallography. Crystals were mounted in a nylon cryoloop using Paratone-N oil under argon gas flow. The data were collected on a Bruker D8 APEX II charge-coupled-device (CCD) diffractometer, with a KRYO-FLEX liquid nitrogen vapor cooling device. The instrument was equipped with a graphite monochromatized MoK $\alpha$ X-ray source $(\lambda=0.71073 \AA)$, with Mono Cap X-ray source optics. Hemispheres of data were collected using $\omega$ scans. Data collection and initial indexing and cell

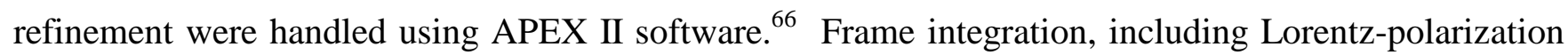
corrections, and final cell parameter calculations were carried out using SAINT+ software. ${ }^{67}$ The data were corrected for absorption using the SADABS program. ${ }^{68}$ Decay of reflection intensity was monitored by analysis of redundant frames. The structure was solved using Direct methods and difference Fourier techniques. Unless otherwise noted, non-hydrogen atoms were refined anisotropically and hydrogen atoms were treated as idealized contributions. Residual electron density originating from solvent contributions was removed using SQUEEZE/PLATON. ${ }^{69}$ Structure solution, refinement, graphics, and creation of publication materials were performed using SHELXTL. ${ }^{70}$

X-Ray Absorption Spectroscopy. X-ray absorption spectroscopy samples were prepared in an inert-atmosphere drybox by dissolving the compound in a 4:1 (by volume) dried toluene/polystyrene solution. Compound mass was determined by the available sample, and produced absorption steps $\Delta \mu \mathrm{t}$ across the uranium $L_{\mathrm{III}}$-edge between 0.2 and 1.1. Once dissolved, the solution was inserted into a multislot aluminum holder, where it was allowed to evaporate overnight. The holder was then capped with indium-sealed aluminized-mylar windows. This sample holder was then sealed in an argon-filled jar until just before measurement at SSRL, Beamline 11-2 with $\operatorname{Si}(220) \varphi=0$ crystals in unfocused mode and energy resolution $\left(\sim 3 \mathrm{eV}\right.$, much better than the $\mathrm{U} 2 \mathrm{p}_{3 / 2}$ core-hole lifetime of $\left.8.7 \mathrm{eV}\right)$. Data were collected at $20 \mathrm{~K}$ in a liquid He-flow cryostat with a $\mathrm{UO}_{2}$ reference. The first derivative of the $L_{\mathrm{III}}$-edge XANES for these reference spectra was set to $17166 \mathrm{eV}$ for one trace. Subsequent data were energycalibrated by fitting the reference data to this one trace. 
Acknowledgment. For financial support of this work, we acknowledge the Division of Chemical Sciences, Office of Basic Energy Sciences, Heavy Element Chemistry program, LANL (Director’s, Agnew National Security and Frederick Reines Postdoctoral Fellowships), the LANL G. T. Seaborg Institute for Transactinium Science, and the LANL Laboratory Directed Research \& Development program. This work was carried out under the auspices of the NNSA of the U.S. DOE at LANL under Contract DE-AC5206NA25396. Work at LBNL was supported by the Director, Office of Science, Office of Basic Energy Sciences, of the U.S. DOE under Contract No. DE-AC02-05CH11231. Drs. Stosh A. Kozimor and Rebecca M. Chamberlin (LANL) are acknowledged for helpful discussions.

Supporting Information Available: Crystallographic information in CIF format for 8, 9a and 10b; magnetic data for complexes $5 \mathbf{b}, \mathbf{6 a}-\mathbf{b}, 7 \mathbf{a}-\mathbf{b}, \mathbf{8}, 9 \mathbf{b}$ and $10 \mathbf{a}$. 


\section{References.}

(1) Denecke, M. A.; Panak, P. J.; Burdet, F.; Weigl, M.; Geist, A.; Klenze, R.; Mazzanti, M.; Gompper, K. C. R. Chim. 2007, 10, 872-882.

(2) Mehdoui, T.; Berthet, J.-C.; Thuery, P.; Salmon, L.; Riviere, E.; Ephritikhine, M. Chem.-Eur. J. 2005, 11, 6994-7006.

(3) Cantat, T.; Arliguie, T.; Noel, A.; Thuery, P.; Ephritikhine, M.; Le Floch, P.; Mezailles, N. J. Am. Chem. Soc. 2009, 131, 963-972.

(4) Arliguie, T.; Belkhiri, L.; Bouaoud, S.-E.; Thuery, P.; Villiers, C.; Boucekkine, A.; Ephritikhine, M. Inorg. Chem. 2009, 48, 221-230.

(5) Kiplinger, J. L.; Morris, D. E.; Scott, B. L.; Burns, C. J. Organometallics 2002, 21, 3073-3075.

(6) Jantunen, K. C.; Burns, C. J.; Castro-Rodriguez, I.; Da Re, R. E.; Golden, J. T.; Morris, D. E.; Scott, B. L.; Taw, F. L.; Kiplinger, J. L. Organometallics 2004, 23, 4682-4692.

(7) Clark, A. E.; Martin, R. L.; Hay, P. J.; Green, J. C.; Jantunen, K. C.; Kiplinger, J. L. J. Phys. Chem. A 2005, 109, 5481-5491.

(8) Da Re, R. E.; Jantunen, K. C.; Golden, J. T.; Kiplinger, J. L.; Morris, D. E. J. Am. Chem. Soc. 2005, 127, 682-689.

(9) Burdet, F.; Pecaut, J.; Mazzanti, M. J. Am. Chem. Soc. 2006, 128, 16512-16513.

(10) Nocton, G.; Horeglad, P.; Pecaut, J.; Mazzanti, M. J. Am. Chem. Soc. 2008, 130, 16633-16645.

(11) Choppin, G. R.; Jensen, M. P. Actinides in Solution: Complexation and Kinetics; $3^{\text {rd }}$ ed.; Springer: Dordrecht, 2006.

(12) Roussel, P.; Hitchcock, P. B.; Tinker, N.; Scott, P. Chem. Commun. 1996, 2053-2054.

(13) Cotton, F. A.; Marler, D. O.; Schwotzer, W. Inorg. Chem. 1984, 23, 4211-4215.

(14) Duval, P. B.; Burns, C. J.; Buschmann, W. E.; Clark, D. L.; Morris, D. E.; Scott, B. L. Inorg. Chem. 2001, 40, 5491-5496.

(15) Roussel, P.; Scott, P.; D. Tinker, N. J. Alloys Compd. 1998, 271-273, 150-153.

(16) Kaim, W.; Klein, A.; Gloeckle, M. Acc. Chem. Res. 2000, 33, 755-763.

(17) Leverd, P. C.; Nierlich, M. Eur. J. Inorg. Chem. 2000, 1733-1738.

(18) Korobkov, I.; Gambarotta, S.; Yap, G. P. A.; Thompson, L.; Hay, P. J. Organometallics 2001, 20, 54405445.

(19) Salmon, L.; Thuery, P.; Miyamoto, S.; Yamato, T.; Ephritikhine, M. Polyhedron 2006, 25, 2439-2446.

(20) Nocton, G.; Burdet, F.; Pecaut, J.; Mazzanti, M. Angew. Chem., Int. Ed. 2007, 46, 7574-7578.

(21) Nocton, G.; Pecaut, J.; Mazzanati, M. Angew. Chem., Int. Ed. 2008, 47, 3040-3042.

(22) Larch, C. P.; Cloke, F. G. N.; Hitchcock, P. B. Chem. Commun. 2008, 82-84.

(23) Duval, P. B.; Burns, C. J.; Clark, D. L.; Morris, D. E.; Scott, B. L.; Thompson, J. D.; Werkema, E. L.; Jia, L.; Andersen, R. A. Angew. Chem., Int. Ed. 2001, 40, 3357-3361.

(24) Boudreaux, E. A.; Mulay, L. N. Theory and Applications of Molecular Paramagnetism; Wiley: New York, 1976.

(25) Schelter, E. J.; Veauthier, J. M.; Thompson, J. D.; Scott, B. L.; John, K. D.; Morris, D. E.; Kiplinger, J. L. J. Am. Chem. Soc. 2006, 128, 2198-2199.

(26) Kiplinger, J. L.; Pool, J. A.; Schelter, E. J.; Thompson, J. D.; Scott, B. L.; Morris, D. E. Angew. Chem. Int. Ed. 2006, 45, 2036-2041.

(27) Schelter, E. J.; Wu, R.; Scott, B. L.; Thompson, J. D.; Morris, D. E.; Kiplinger, J. L. Angew. Chem. Int. Ed. 2008, 47, 2993-2996.

(28) Schelter, E. J.; Veauthier, J. M.; Graves, C. R.; John, K. D.; Scott, B. L.; Thompson, J. D.; Pool-DavisTournear, J. A.; Morris, D. E.; Kiplinger, J. L. Chem.-Eur. J. 2008, 14, 7782-7790.

(29) Morris, D. E.; Da Re, R. E.; Jantunen, K. C.; Castro-Rodriguez, I.; Kiplinger, J. L. Organometallics 2004, 23, 5142-5153.

(30) Schelter, E. J.; Yang, P.; Scott, B. L.; Thompson, J. D.; Martin, R. L.; Hay, P. J.; Morris, D. E.; Kiplinger, J. L. Inorg. Chem. 2007, 46, 7477-7488.

(31) Schelter, E. J.; Yang, P.; Scott, B. L.; Da Re, R. E.; Jantunen, K. C.; Martin, R. L.; Hay, P. J.; Morris, D. E.; Kiplinger, J. L. J. Am. Chem. Soc. 2007, 129, 5139-5152. 
(32) Hilton, D. J.; Prasankumar, R. P.; Schelter, E. J.; Thorsmølle, V. K.; Trugman, S. A.; Shreve, A. P.; Kiplinger, J. L.; Morris, D. E.; Taylor, A. J. J. Phys. Chem. A 2008, 112, 7840-7847.

(33) Veauthier, J. M.; Schelter, E. J.; Carlson, C. N.; Scott, B. L.; Da Re, R. E.; Thompson, J. D.; Kiplinger, J. L.; Morris, D. E.; John, K. D. Inorg. Chem. 2008, 47, 5841-5849.

(34) Evans, W. J.; Lee, D. S.; Lie, C.; Ziller, J. W. Angew. Chem., Int. Ed. 2004, 43, 5517-5519.

(35) Shannon, R. D. Acta Crystallogr. 1976, A32, 751-767.

(36) D'Alessandro, D. M.; Keene, F. R. Dalton Trans. 2004, 3950-3954.

(37) LeSuer, R. J.; Geiger, W. E. Angew. Chem. Int. Ed. 2000, 39, 248-250.

(38) Kuehl, C. J.; Da Re, R. E.; Scott, B. L.; Morris, D. E.; John, K. D. Chem. Commun. 2003, 2336-2337.

(39) Bard, A. J.; Faulkner, L. R. Electrochemical Methods: Fundamentals and Applications; Wiley: New York, 1980.

(40) Carlson, C. N.; Veauthier, J. M.; John, K. D.; Morris, D. E. Chem.-Eur. J. 2008, 14, 422-431.

(41) Carlson, C. N.; Kuehl, C. J.; Da Re, R. E.; Veauthier, J. M.; Schelter, E. J.; Milligan, A. E.; Scott, B. L.; Bauer, E. D.; Thompson, J. D.; Morris, D. E.; John, K. D. J. Am. Chem. Soc. 2006, 128, 7230-7241.

(42) Arana, C. R.; Abruna, H. D. Inorg. Chem. 1993, 32, 194-203.

(43) Collin, J. P.; Laine, P.; Launay, J. P.; Sauvage, J. P.; Sour, A. J. Chem. Soc., Chem. Commun. 1993, 434435.

(44) Hess, N. J.; Weber, W. J.; Conradson, S. D. J. Alloys Compd. 1998, 271-273, 240-243.

(45) Kelly, S. D.; Kemner, K. M.; Carley, J.; Criddle, C.; Jardine, P. M.; Marsh, T. L.; Phillips, D.; Watson, D.; Wu, W.-M. Environ. Sci. Technol. 2008, 42, 1558-1564.

(46) Booth, C. H.; Daniel, M.; Wilson, R. E.; Bauer, E. D.; Mitchell, J. N.; Moreno, N. O.; Morales, L. A.; Sarrao, J. L.; Allen, P. G. J. Alloys Compd. 2007, 444-445, 119-123.

(47) Kozimor, S. A.; Yang, P.; Batista, E. R.; Boland, K. S.; Burns, C. J.; Christensen, C. N.; Clark, D. L.; Conradson, S. D.; Hay, P. J.; Lezama, J. S.; Martin, R. L.; Schwarz, D. E.; Wilkerson, M. P.; Wolfsberg, L. E. Inorg. Chem. 2008, 47, 5365-5371.

(48) Kozimor, S. A.; Yang, P.; Batista, E. R.; Boland, K. S.; Burns, C. J.; Clark, D. L.; Conradson, S. D.; Martin, R. L.; Wilkerson, M. P.; Wolfsberg, L. E. J. Am. Chem. Soc. 2009, 131, 12125-12136.

(49) Graves, C. R.; Yang, P.; Kozimor, S. A.; Vaughn, A. E.; Clark, D. L.; Conradson, S. D.; Schelter, E. J.; Scott, B. L.; Thompson, J. D.; Hay, P. J.; Morris, D. E.; Kiplinger, J. L. J. Am. Chem. Soc. 2008, 130, 5272-5285.

(50) Meyer, K.; Bart, S. C. Adv. Inorg. Chem. 2008, 60, 1-30.

(51) Fillaux, C.; Berthet, J.-C.; Conradson, S. D.; Guilbaud, P.; Guillaumont, D.; Hennig, C.; Moisy, P.; Roques, J.; Simoni, E.; Shuh, D. K.; Tyliszczak, T.; Castro-Rodriguez, I.; Den Auwer, C. C. R. Chim. 2007, 10, 859-871.

(52) Graves, C. R.; Scott, B. L.; Morris, D. E.; Kiplinger, J. L. J. Am. Chem. Soc. 2007, 129, 11914-11915.

(53) Conradson, S. D.; Abney, K. D.; Begg, B. D.; Brady, E. D.; Clark, D. L.; Den Auwer, C.; Ding, M.; Dorhout, P. K.; Espinosa-Faller, F. J.; Gordon, P. L.; Haire, R. G.; Hess, N. J.; Hess, R. F.; Keogh, D. W.; Lander, G. H.; Lupinetti, A. J.; Morales, L. A.; Neu, M. P.; Palmer, P. D.; Paviet-Hartmann, P.; Reilly, S. D.; Runde, W. H.; Tait, C. D.; Veirs, D. K.; Wastin, F. Inorg. Chem. 2004, 43, 116-131.

(54) Herbst, J. F.; Wilkins, J. W. Phys. Rev. B: Condens. Matter 1988, 38, 1027-1039.

(55) Allen, P. G.; Bucher, J. J.; Shuh, D. K.; Edelstein, N. M.; Reich, T. Inorg. Chem. 1997, 36, 4676-4683.

(56) Kalkowski, G.; Kaindl, G.; Brewer, W. D.; Krone, W. Phys. Rev. B: Condens. Matter 1987, 35, 26672677.

(57) Hu, Z.; Kaindl, G.; Meyer, G. J. Alloys Compd. 1998, 274, 38-41.

(58) Fagan, P. J.; Manriquez, J. M.; Maatta, E. A.; Seyam, A. M.; Marks, T. J. J. Am. Chem. Soc. 1981, 103, 6650-6667.

(59) Barriere, F.; LeSuer, R. J.; Geiger, W. E. Trends Mol. Electrochem. 2004, 413-444.

(60) LeSuer, R. J.; Buttolph, C.; Geiger, W. E. Anal. Chem. 2004, 76, 6395-6401.

(61) Nafady, A.; Costa, P. J.; Calhorda, M. J.; Geiger, W. E. J. Am. Chem. Soc. 2006, 128, 16587-16599.

(62) Barriere, F.; Geiger, W. E. J. Am. Chem. Soc. 2006, 128, 3980-3989.

(63) Evans, W. J.; Grate, J. W.; Choi, H. W.; Bloom, I.; Hunter, W. E.; Atwood, J. L. J. Am. Chem. Soc. 1985, 107, 941-946.

(64) Tilley, T. D.; Boncella, J. M.; Berg, D. J.; Burns, C. J.; Andersen, R. A. Inorg. Synth. 1990, 27, $146-150$.

(65) Veauthier, J. M.; Carlson, C. N.; Collis, G. E.; Kiplinger, J. L.; John, K. D. Synthesis 2005, 2683-2686.

(66) APEX II, Bruker Analytical X-Ray Systems: Madison, WI, 1997.

(67) SAINT+, Integration Software; Bruker Analytical X-Ray Systems: Madison, WI, 2003. 
(68) Sheldrick, G. M. SADABS 2.03, Program for Absorption Correction; University of Göttingen: Göttingen, Germany, 2001.

(69) Spek, A. L., PLATON-A Multipurpose Crystallographic Tool; Utrecht University: Utrecht, The Netherlands, 2005.

(70) Sheldrick, G. M. SHELXTL 5.10, Structure Solution and Refinement Package; University of Göttingen: Göttingen, Germany, 1997. 


\section{For Table of Contents Use Only}

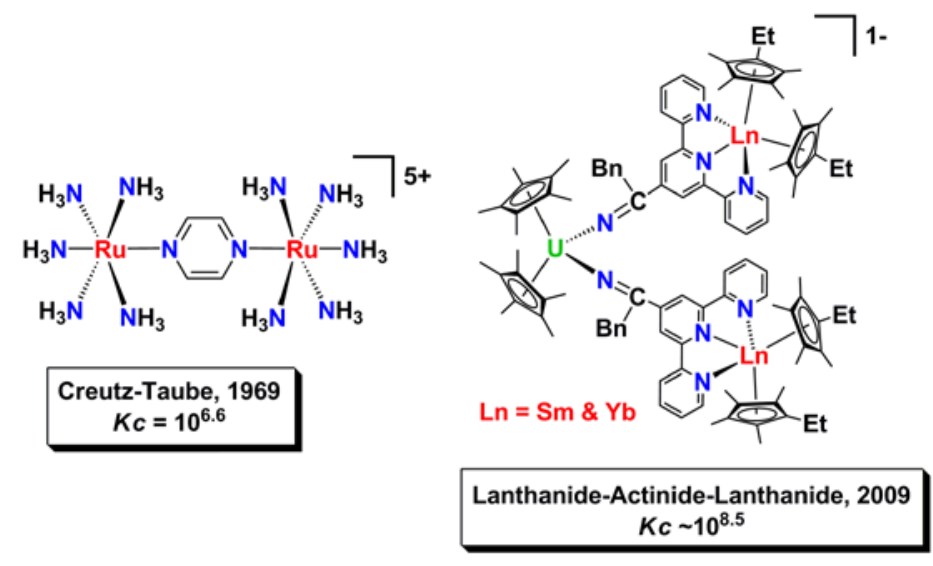

Multimetallic actinide and lanthanide complexes have been synthesized to study f-electron delocalization within an isostructural molecular framework. Evidence for 5f/6d-orbital covalency is clearly seen on comparison of $4 \mathrm{f}$ and $5 \mathrm{f}$ complexes. Electrochemical data indicate electronic delocalization within the molecular framework with the appearance of strong electronic coupling for the trimetallic $\left[\mathrm{Yb}^{\mathrm{III}}-\mathrm{U}^{\mathrm{IV}}-\mathrm{Yb}^{\mathrm{III}}\right]^{-}, \quad\left[\mathrm{Sm}^{\mathrm{III}}-\mathrm{U}^{\mathrm{IV}}-\mathrm{Sm}^{\mathrm{III}}\right]^{-}$, and $\left[\mathrm{La}^{\mathrm{III}}-\mathrm{U}^{\mathrm{IV}}-\mathrm{La}^{\mathrm{III}}\right]^{-}$systems whose calculated comproportionation constant $K_{c}$ is slightly larger than that reported for the benchmark Creutz-Taube ion. 